UNIVERSIDADE DE SÃO PAULO

FACULDADE DE FILOSOFIA, LETRAS E CIÊNCIAS HUMANAS

DEPARTAMENTO DE FILOSOFIA

PROGRAMA DE PÓS-GRADUAÇÃO

Patrícia Fernandes Battilani

\title{
O DEBATE DA IMAGÉTICA MENTAL
}


Patrícia Fernandes Battilani

\section{O DEBATE DA IMAGÉTICA MENTAL}

Dissertação apresentada ao Programa de PósGraduação em Filosofia do Departamento de Filosofia da Faculdade de Filosofia, Letras e Ciências Humanas da Universidade de São Paulo, como parte dos requisitos para a obtenção do título de Mestre em Filosofia.

Orientador: Osvaldo Frota Pessoa Junior 
Dedico essa dissertação

a Marcos Romeo Bertola, aos meus pais e à memória de Márcia Fleury de Souza Lima 


\section{Agradecimentos}

Gostaria de agradecer as pessoas que me ajudaram a tornar esse trabalho possível, tais como o meu orientador e professor de graduação, prof. Dr. Osvaldo Pessoa Jr., o amigo e secretário do Departamento de Filosofia, Ruben Sosa Cabrera Jr., os meus professores da graduação, em especial os professores Caetano Plastino e João Vergilio Cuter, que me orientaram na iniciação científica e acompanharam o meu trabalho. Agradeço ainda à CAPES e aos chefes do Departamento de Filosofia, em especial aos professores Marco Zingano, Pablo Ruben Mariconda e Moacyr Novaes, pela manutenção do programa de iniciação científica que têm levado, no decorrer da história do departamento, alunos de graduação a perseguir uma carreira acadêmica no futuro. Agradecimentos aos funcionários da secretaria do Departamento de Filosofia, da seção de alunos e da Biblioteca Florestan Fernandes, bem como aos meus colegas de graduação e amigos que tiveram papel nesse trabalho. Agradeço aos professores João Kogler, Mariana Broens, Hamilton Haddad e especialmente ao meu orientador pelas suas contribuições para o texto final da dissertação. Agradeço por fim aos meus pais e familiares pelo apoio e a Marcos Romeo Bertola, sem o qual esse trabalho não teria sido possível. 


\section{Resumo}

Battilani, P. F. O debate da imagética mental. 2013. 81 f. Dissertação (Mestrado) Faculdade de Filosofia, Letras e Ciências Humanas. Departamento de Filosofia, Universidade de São Paulo, São Paulo, 2013.

O debate da imagética mental consiste de uma controvérsia iniciada nos anos 1970 a respeito da forma das representações mentais, e foi travada principalmente entre Stephen Kosslyn, que propunha uma forma imagética, e Zenon Pylyshyn, que propunha um formato simbólico-estrutural, além de apontar falhas conceituais na "teoria da afiguração" implícita no modelo pictorialista. Nesta dissertação, apresenta-se um balanço filosófico deste debate, levando em conta também críticas adicionais de Daniel Dennett aos pressupostos da abordagem pictorialista.

Palavras-chave: Debate da imagética mental. Teoria da afiguração. Qualia. Stephen Kosslyn. Zenon Pylyshyn. Daniel Dennett. 


\begin{abstract}
Battilani, P. F. The imagery debate. 2013. 81 f. Thesis (Master Degree) Faculdade de Filosofia, Letras e Ciências Humanas. Departamento de Filosofia, Universidade de São Paulo, São Paulo, 2013.

The mental imagery debate is a controversy that began in the 1970's concerning the form of mental representation, and was carried out mainly by Stephen Kosslyn, who defended a picture-like representation, and Zenon Pylyshyn, who proposed a symbolicstructural format. The latter also pointed out conceptual problems of the pictorialist model. This thesis presents a philosophical discussion of the debate, also taking into account additional criticisms by Daniel Dennett to the presuppositions of the pictorialist approach.
\end{abstract}

Keywords: Mental imagery debate. Picture-like representation. Qualia. Stephen Kosslyn. Zenon Pylyshyn. Daniel Dennett. 


\section{Sumário}

Introdução

Cap. 1: $O$ debate sobre imagens mentais

1.1 Inteligência artificial e universalidade $\quad 10$

1.2 Quatro fases do debate sobre as imagens mentais 12

1.3 Experimento de escaneamento mental e discussões 15

1.4 A contribuição das técnicas de imageamento cerebral 20

\section{Cap.2: A teoria de Kosslyn da representação por imagens}

2.1 Propriedades privilegiadas das imagens mentais

2.2 O problema da representação interna 27

2.3 A relação representacional 32

2.4 A analogia computacional no modelo pictorialista 36

$2.5 \mathrm{O}$ espaço funcional 39

\section{Cap. 3: As críticas de Pylyshyn à teoria da afiguração}

3.1 Crítica ao panorama interno e ao olho da mente 43

3.2 Linguagem do pensamento e experiência imagética 47

3.3 Conhecimento tácito versus arquitetura cognitiva 51

3.4 O problema da conexão entre percepção e mundo 54

\section{Cap. 4: Outras críticas à teoria da afiguração}

4.1 A crítica de Noë à concepção fotográfica da teoria visual 56

4.2 Discussão sobre o tamanho e resolução da imagem mental 57

4.3 A crítica de Dennett ao teatro cartesiano 59

4.4 O problema dos qualia e a cegueira a mudança 65

4.5 Crítica aos qualia através de experimentos mentais 71

$\begin{array}{ll}\text { Conclusões } & 75\end{array}$

$\begin{array}{ll}\text { Bibliografia } & 77\end{array}$ 


\section{Introdução}

Existem figuras no cérebro? É razoável falar num "olho da mente" que observa imagens projetadas pelo sistema visual periférico numa tela [display] interna?

Para resolver um problema visual corriqueiro, como estacionar o carro numa vaga, pode-se considerar que esta imagem interna é manipulada de variadas formas, envolvendo varredura [scanning], rotação, sobreposição ou projeção? Afinal, qual a natureza da experiência imagética? Quando físicos como Einstein ou Feynman (2006) afirmam que resolvem problemas com mais facilidade por referência a imagens, o que está por trás dessa capacidade inegável? É possível falar num tipo de representação por trás das imagens (ou da experiência das imagens), como uma oposição entre representações imagéticas ou pictóricas (Kosslyn et al., 2002), por um lado, e simbólicas (ou language-like) (Pylyshyn, 2003), por outro, ou essa dicotomia é na verdade enganadora? O que se pode dizer sobre os correlatos neurais das imagens? Será que os dados das neurociências (como os avanços em imageamento do cérebro) podem realmente decidir entre uma teoria imagética e uma simbólica, no caso da representação visual?

A presente dissertação se inicia com uma apresentação do debate da imagética, em que se resumem as quatro fases do debate sobre as imagens mentais, travada principalmente entre Stephen Kosslyn e Zenon Pylyshyn. Nesse primeiro capítulo, apresentam-se os experimentos básicos de escaneamento mental, além de considerações sobre a inteligência artificial e técnicas de imageamento cerebral.

O segundo capítulo entra em considerações mais detalhadas sobre a teoria de Kosslyn da representação por imagens, em que se exploram problemas relacionados com a representação interna e a introdução da noção de "espaço funiconal". No terceiro 
capítulo, são apresentadas as principais críticas de Pylyshyn à teoria da afiguração, e suas noções de conhecimento tácito e linguagem de pensamento.

O quarto capítulo apresenta críticas adicionais à teoria da afiguração, como as de Noë e Dennett, envolvendo o experimento de cegueira a mudança, e experimentos mentais que criticam as noções de qualia e de um Teatro Cartesiano, implícitos na abordagem pictorialista. 


\section{Capítulo 1}

\section{O debate sobre imagens mentais}

\subsection{Inteligência artificial e universalidade}

O debate ou debates sobre imagens mentais surgiu de uma controvérsia sobre a forma das representações na mente iniciada nos anos 1970 entre Zenon Pylyshyn (proponente da tese segundo a qual as representações mentais teriam formato exclusivamente simbólico-estrutural) e Stephen Kosslyn (defensor da tese de que há representações em formato pictórico).

Esse debate pode ser compreendido no contexto de um entusiasmo com a inteligência artificial, a partir dos anos 1950, que sustentava que a melhor forma de explicar o comportamento da mente humana seria programar um computador que pudesse imitar o seu funcionamento, ou as funções que se desejava estudar.

No caso da imagética, isso gerou uma série de questões conceituais sobre a própria natureza das representações:

Para imitar imagens mentais é preciso especificar uma representação imagética com propriedades particulares; uma representação é um tipo de código, uma forma de especificar informação. Essa abordagem nos força a pensar claramente sobre a natureza de tais representações. Assim que esse método se tornou cada vez mais popular, pesquisadores se tornaram conscientes de que havia muitas formas de programar um computador para imitar imagens. E isso logo resultou numa série de debates sobre a natureza das representações mentais. (Kosslyn, 1994, p. 4)

A inteligência artificial surgiu nas décadas de 1950 e 1960 como área da computação voltada para a elaboração de softwares que desempenhassem tarefas semelhantes às consideradas "inteligentes" no ser humano, como dedução lógica, jogos 
de tabuleiro (como damas e xadrez), processamento de linguagem natural, etc. Os envolvidos na pesquisa em inteligência artificial nesse período concebiam que o ser humano, tal como um computador, também é um processador de informação, e assim “deveria ser possível estudar os seus processos e sua organização independentemente dos detalhes dos mecanismos biológicos - o 'hardware' - que os implementa” (Simon \& Newell, 1964, p. 281).

Um desdobramento desse tipo de abordagem foi a possibilidade de testar teorias do pensamento humano através da implementação dessas teorias como programas computacionais, examinando os outputs dos computadores programados dessa maneira. Pylyshyn (1989) também ressaltou a importância do uso da computação para estudar fenômenos mentais, devido ao seu auxílio na criação de modelos para compreender fenômenos observáveis e internos.

Neste contexto de processamento de informação, veremos nos capítulos seguintes como diferentes modelos de pensamento (o simbólico-estrutural, o da linguagem de pensamento e o imagético) foram desenvolvidos sob a inspiração de modelos computacionais, suscitando o debate filosófico a respeito da natureza do pensamento humano.

Os diferentes modelos computacionais da mente podem se considerados uma espécie de "jogo lógico", no qual signos sem sentido intrínseco são manipulados de acordo com regras formais (ou sintáticas). Isso é devido à noção de "universalidade" surgida nos trabalhos sobre as fundações da matemática nos anos 1930 (com Gödel, Turing, Church e Post), e que foram assimiladas pela inteligência artificial. A universalidade implica que uma máquina ideal pode processar símbolos formais e produzir uma ampla gama de funções, chamadas recursivas, fornecendo outputs específicos a partir dos inputs. Na prática, nenhum sistema físico finito possui a 
capacidade de uma máquina ideal, mas o importante é a noção de que a função pode ser computada da mesma maneira, qualquer que seja o substrato material, um cérebro vivo ou uma máquina mecânica com chips de silício (Pylyshyn, 1989).

Em suma, é possível programar computadores para computar qualquer função matemática (de maneira aproximada, dentro das restrições do tamanho finito do sistema), e essas computações podem ser tomadas como uma simulação dos processos cerebrais, ou mesmo uma "emulação" do processos mentais (segundo uma concepção funcionalista). É essa mesma estratégia de simulação que norteará os diferentes lados do debate sobre a natureza do pensamento humano, seja a teoria da "linguagem do pensamento" de Pylyshyn, seja o modelo imagético de Kosslyn.

\subsection{Quatro fases do debate sobre as imagens mentais}

Podem-se dividir os debates sobre imagens mentais em quatro fases, cada uma delas concentrando-se num aspecto da discussão, sendo que Kosslyn (proponente da tese pictorialista), numa de suas publicações mais recentes e já na quarta fase desse debate, afirma que a discussão teria se encerrado nesta fase devido aos avanços nas técnicas em imageamento do cérebro (agora que se saberia o que são e onde estão as imagens na mente) (Kosslyn et al., 2006, p. 6)

A primeira fase iniciou-se com a crítica feita por Pylyshyn (1973) de que a "metáfora pictórica" usada em discussões sobre a imagética visual mental estava equivocada. $\mathrm{O}$ experimento mais importante da época, a favor do programa de pesquisa pictorialista, foi o experimento da rotação mental, realizado por Roger Shepard \& Jacqueline Metzler (1971), no Departamento de Psicologia da Universidade de Stanford. 
Tal experimento se baseava em mostrar aos sujeitos pares de figuras bidimensionais retratando formas geométricas tridimensionais, como os da Fig. 1a. Os sujeitos deveriam decidir se as figuras mostradas eram idênticas. Para isso, supostamente, realizariam uma rotação das figuras geométricas em suas mentes, sobrepondo-as, se necessário, para tomar a decisão correta. Caso tal rotação ocorresse, segundo a hipótese dos investigadores, observar-se-ia que quanto maior o ângulo de rotação, mais tempo essa tarefa levaria. Os resultados apresentados estão na Fig. 1b, que confirmam a previsão que se segue da hipótese da rotação mental.
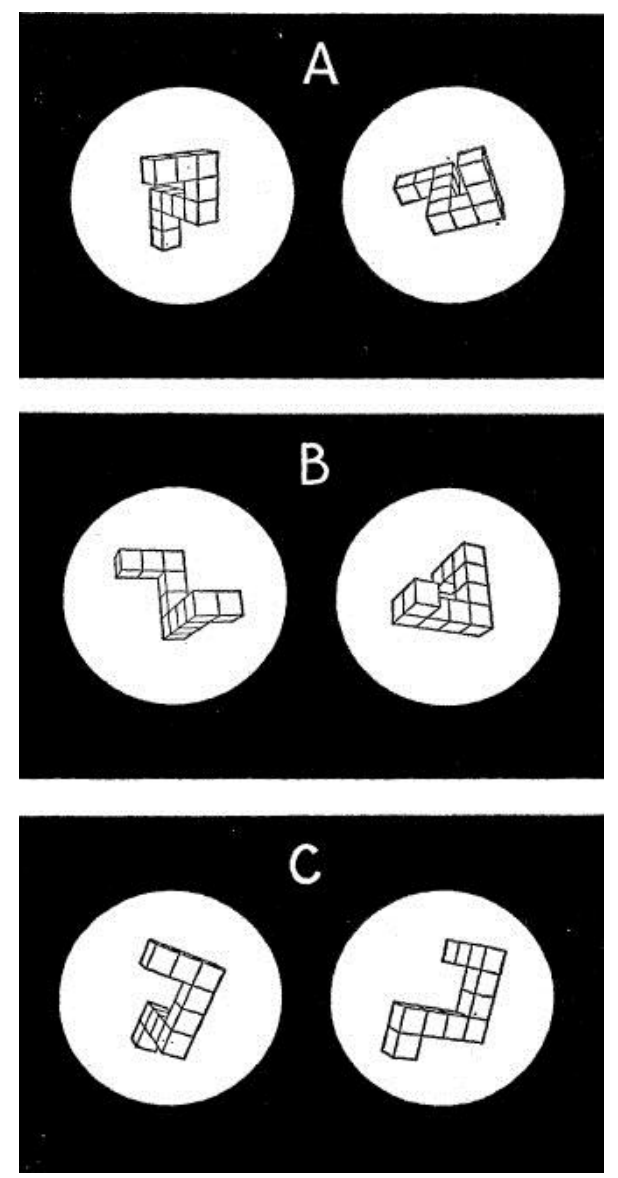

Figura 1a: Exemplos de pares de figuras mostradas aos sujeitos. (A) Par "idêntico", diferindo por rotação de $80^{\circ}$ no plano da figura. (B) Par "idêntico", diferindo por rotação de $80^{\circ} \mathrm{em}$ profundidade. (C) Par "diferente".

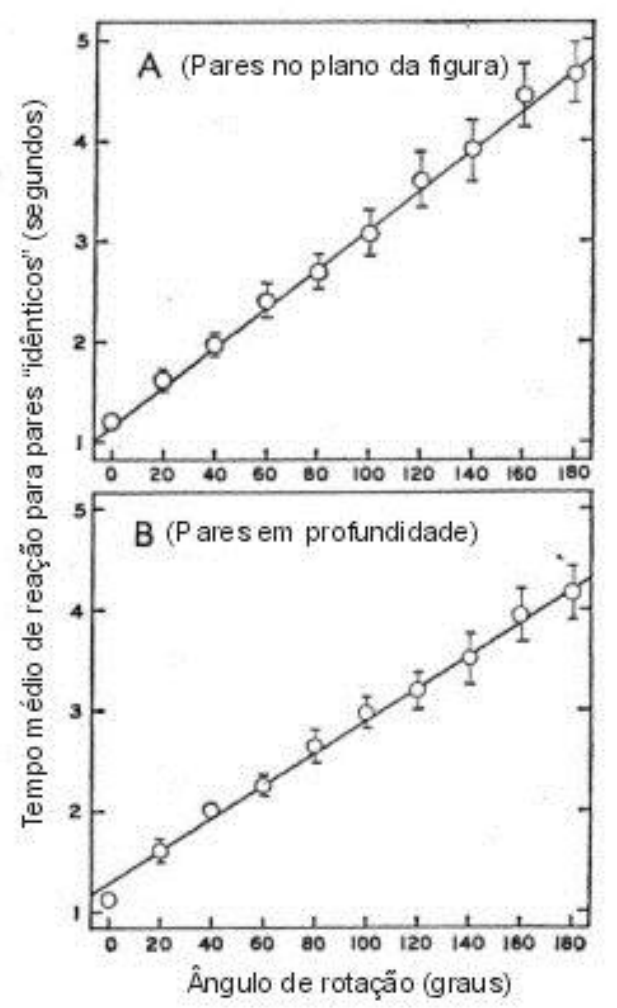

Figura 1b: Gráficos dos tempos médio de reação para obtenção da resposta, em função da diferença angular entre as figuras, para os casos (A) e (B) da Fig. la.

(Shepard \& Metzler, 1971, p. 702). 
Para Kosslyn, as conclusões depreendidas desse experimento, assim como as extraídas do estudo do escaneamento mental de imagens,

não somente validam a introspecção de que os objetos nas imagens parecem girar, passando por posições intermediárias ao longo de uma trajetória, e portanto requerendo mais tempo para girar; mas também nos dizem coisas que simplesmente não são aparentes para a introspecção. Por exemplo, o tempo de rotação aumentou linearmente com o ângulo no qual a figura foi girada [...] (Kosslyn, 1983, p. 39).

Pylyshyn (1973), porém, argumentava que a "metáfora pictórica" usada em nessa discussão estava equivocada, e que seria preciso reconhecer que as estruturas mentais fundamentais são conceituais, simbólicas, descritivas e proposicionais, e não sensoriais ou pictóricas. Pylyshyn apontou que o vocabulário sobre imagética leva a enganos conceituais, tais como sugerir que a própria imagem é, em si, um "ente a ser percebido". Esse autor questiona ainda "se o conceito de imagem [mental] pode ser usado como um construto explicativo primitivo (isto é, que não exija outras reduções) em teorias psicológicas da cognição" (Pylyshyn, 1973, p. 2).

$\mathrm{Na}$ segunda fase do debate, Kosslyn e seus colaboradores responderam às críticas de Pylyshyn e outros, propondo uma série de novos experimentos comportamentais, tais como o do "escaneamento" (varredura) mental de imagens (Denis \& Kosslyn, 1999), um estudo do "ângulo visual do olho da mente" (Kosslyn, 1978), e outros experimentos envolvendo imagem mental (Kosslyn, 1975), que pudessem comprovar a hipótese pictórica. Discutiremos alguns desses experimentos na seção seguinte (1.3).

Nesta fase do debate, a preocupação estava relacionada à explicação dos resultados empíricos obtidos, discutindo diferentes hipóteses sobre o que estaria por trás da experiência das imagens, e discutindo possíveis problemas metodológicos 
relacionados à interpretação dos experimentos. Zenon Pylyshyn, Ned Block e Michael Tye foram alguns dos críticos que levantaram problemas conceituais envolvidos com a tese pictorialista. Tanto esta quanto as fases subsequentes consistiram "numa troca entre discussões filosóficas e pesquisa empírica” (Kosslyn, 1994, p. 4)

Uma dos argumentos usados por Pylyshyn para explicar os resultados obtidos pelos experimentos, elaborados para corroborar a tese pictorialista, foi a hipótese de que é o conhecimento tácito dos sujeitos que lhes permitia responder às tarefas dadas pelos estudiosos da imagética, que lhes permitia conceber o que ocorreria na percepção (Pylyshyn, 1981). Voltaremos a este conceito em breve.

Na terceira fase, houve uma resposta às dificuldades conceituais e metodológicas levantadas, a partir dos novos métodos da neurociência, principalmente avanços nas técnicas de imageamento do cérebro, que forneceram dados que traziam dificuldades para a hipótese do conhecimento tácito. Discutiremos a contribuição das técnicas de imageamento cerebral na seção 1.4.

A quarta fase se iniciou em 2002, com novas críticas de Pylyshyn, desta vez argumentando que "apesar do interesse intrínseco desses achados [de neuroimageamento], os mesmos não apoiam a existência de qualquer tipo de tela afiguradora [depictive display] na imagética mental” (Pylyshyn, 2002, p. 159).

\subsection{Experimento de escaneamento mental e discussões}

Apesar do impacto do experimento da rotação mental de Shepard \& Metzler, visto na seção anterior, em favor da concepção pictorialista, alguns autores como Anderson (1978) argumentaram que ele poderia ser explicado de maneira proposicional: 
“Os resultados da rotação mental poderiam ser devidos [...] a descrições proposicionais das figuras, descrições essas que se alteram gradualmente, de forma que diferentes orientações sejam representadas" (Kosslyn, 1983, p. 41). Neste caso, as propriedades pictóricas da experiência imagética seriam um mero epifenômeno, nada dizendo sobre a real representação mental.

Para superar esta crítica, o grupo de Kosslyn, também trabalhando na Universidade de Stanford, elaborou uma série de experimentos que exploravam previsões da teoria pictorialista. O primeiro experimento envolveu a memorização de desenhos de objetos, em que aparecem alguns detalhes mas não outros (por exemplo, um avião é desenhado com uma hélice e uma antena, mas sem um motor ou rodas aparentes). Os tempos que os sujeitos demoraram para responder às perguntas eram proporcionais às distâncias entre as partes de cada figura, o que corroborava a hipótese pictorialista. Porém, o pesquisador em inteligência artificial Danny Bobrow conseguiu fornecer uma hipotética explicação em termos apenas proposicionais, na qual as representações dos conceitos correspondentes às partes dos objetos estão estruturadas de certa maneira, de tal forma que a passagem mental de um conceito para outro pode envolver outros conceitos intermediários, aumentando o tempo para resolver o problema (Kosslyn, 1983, pp. 43-4).

Após mais alguns experimentos de escaneamento mental de imagens, Kosslyn, Ball \& Reiser (1978) chegaram à forma mais elaborada do experimento (ver também Denis \& Kosslyn, 1999). Eles apresentaram para os participantes a imagem de um mapa de uma ilha (ver Fig. 2a), em que sete objetos eram representados em diferentes locais, com diferentes distâncias entre eles. 


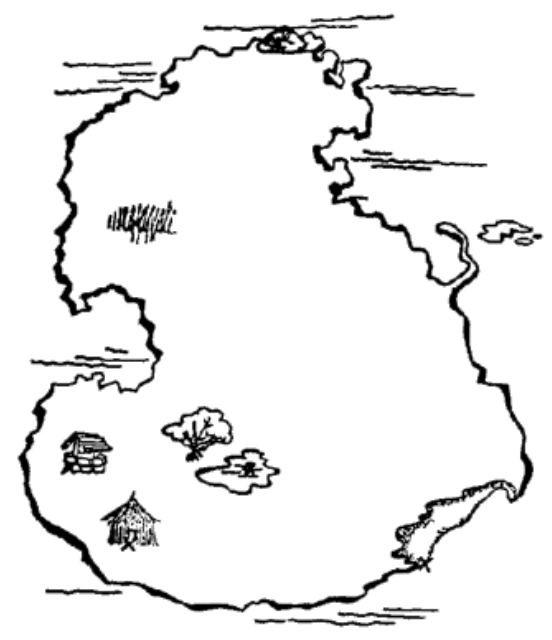

Figura 2a: Mapa da ilha usado no experimento de Kosslyn, Ball \& Reiser (1978).

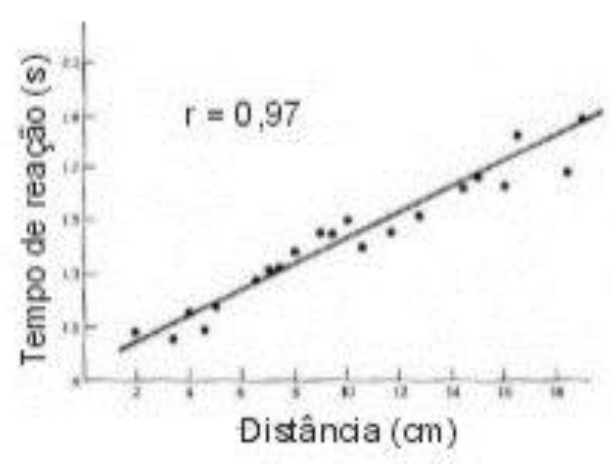

Figura 2b: Tempo médio de reação em função da distância envolvida no mapa. $O$ valor de rindica a qualidade do ajusta linear dos pontos.

Os participantes aprendiam a desenhar o mapa e as posições dos sete objetos. Depois da memorização, os participantes fechavam os olhos e ouviam o nome de um dos objetos, que passava a ser o foco de sua atenção. Em seguida, ouviam o nome de outro objeto, que poderia estar ou não no mapa. A tarefa dos participantes era imaginar um ponto preto voando do primeiro para o segundo objeto, e quando este ponto chegasse no segundo objeto, eles apertariam um botão. Se o segundo objeto não estivesse no mapa, um outro botão seria apertado.

A conclusão do estudo foi de que o tempo para escanear a imagem aumenta linearmente com a distância entre os pontos (Fig. 2b). Este resultado é o previsto pela hipótese de que a representação mental de imagens dispõe a informação em duas dimensões espaciais.

Esta versão do experimento de escaneamento mental de imagens foi então capaz de escapar da explicação de Bobrow, pois um mapa geográfico contém distâncias, cujas diferenças quantitativas não poderiam ser representadas por diferentes cadeias de 
conceitos (para dar conta dos diferentes tempos envolvidos para responder às perguntas):

A falha no primeiro [experimento] foi a relação entre a distância espacial e o número de características do desenho: ao escanear distâncias maiores, os sujeitos também escaneavam mais características. O que tínhamos de fazer, então, era encontrar uma maneira da avaliar os efeitos apenas da distância (Kosslyn, 1983, p. 45).

Esse experimento, assim como muitos outros realizados pelo programa de pesquisa de Kosslyn, impressionaram tanto os proponentes da tese pictorialista que passaram a ser considerados "uma janela na mente" (Denis \& Kosslyn, 1999), indicando as convicções dos autores de que havia-se obtido evidências de uma observação direta das estruturas representacionais imagéticas por trás da experiência das imagens visuais.

A teoria pictorialista também estendeu a hipótese da tela interna para quando os estímulos do ambiente não estão presentes. Neste caso, haveria um preenchimento dessa tela a partir de funções internas, tais como memória ou pensamento. A ideia por trás da postulação pictorialista de uma representação de tipo imagética, que vivenciamos quando temos imagens mentais e que utilizamos em variadas tarefas, é que ela é uma experiência muito semelhante à da visão. Assim, supõe-se que entreter uma imagem na mente deve envolver algum tipo de visão interna.

Pylyshyn não aceitou essas conclusões, em sua crítica ao modelo pictorialista, discordando da interpretação de Kosslyn de que haveria uma imagem realmente posta num espaço real no córtex, de tal maneira que a atenção pudesse passar ou escanear por essa imagem, como se se tratasse de um espaço real externo. Para Pylyshyn, não há restrições ou imposições (tal como a de distância) advindas da arquitetura cognitiva, que constrangesse uma imagem mental: esta poderia ser imaginada como o sujeito quisesse. 
Agora, se você imaginar uma bolinha [spot] se movendo através da sua imagem da sua cena favorita, você notará que leva mais tempo para ir mais à frente. Mas você poderia também notar que você pode fazer a bolinha acelerar, desacelerar, voltar atrás, pular para diferentes lugares, desaparecer da cena e fazer qualquer tipo de truque que você quiser. Trata-se não somente da sua imagem, mas de sua bolinha, com a qual você pode fazer com ele o que quiser - o movimento da bolinha não está restrito de maneira alguma por propriedades do seu sistema imagético (Pylyshyn, 2007, p. 134).

A pergunta feita por Pylyshyn é por que os sujeitos agem da maneira que fazem, apresentando a regularidade encontrada nos experimentos de escaneamento desenvolvidos por Kosslyn, se poderiam fazer de outra maneira? A resposta oferecida por Pylyshyn evoca o conceito de "conhecimento tácito". Essa noção evoca os conceitos e crenças implícitos que o sujeito tem a respeito do mundo, inclusive o seu conhecimento intuitivo a respeito de leis da física que regem as coisas no mundo.

A favor desse tipo de interpretação, Pylyshyn (1981, p. 135) apresenta um experimento que realizou com Liam Bannon, no qual aos sujeitos era apresentado também um mapa, mas com luzes e botões para ligar e desligar. Quando se apertava o botão apropriado, a luz que estava acesa apagava e outra acendia imediatamente. Da mesma forma que no experimento de Kosslyn, pedia-se aos sujeitos para memorizar o mapa e apertar um botão quando vissem, em sua imagem mental, uma luz que se acendia em outro ponto do mapa. Não houve, nesse caso, aumento de tempo linear com aumento da distância. Isso corrobora a hipótese de Pylyshyn de que não são as propriedades da arquitetura cognitiva do cérebro que fazem com que o tempo de escaneamento seja proporcional à distância (no experimento de Kosslyn), ou constante no experimento que realizou com Bannon.

Em um âmbito mais geral, Pylyshyn elaborou um argumento, que chamou de "hipótese nula", segundo o qual nenhum experimento pode servir de teste refutador contra a teoria proposicional-descritivista, pois as imagens mentalmente manipuláveis 
que os pictorialistas postulam existir podem muito bem terem uma representação mais profunda em termos proposicionais. Citando:

[...] raciocinar com imagens mentais envolve a mesma forma de representação e os mesmos processos que o raciocínio em geral, exceto que o conteúdo dos pensamentos experienciados como imagens incluem informação sobre como as coisas se pareceriam [...]

Neste artigo, defendo uma concepção provisória, que chamo de "hipótese nula”, segundo a qual, no nível relevante de análise - o nível apropriado para explicar os resultados de muitos experimentos sobre imagens mentais - o processo de raciocínio imagético envolve os mesmos mecanismos e as mesmas formas de representação que estão envolvidos no raciocínio em geral, mesmo que com diferentes conteúdos ou assuntos. Essa hipótese afirma que o que é especial sobre o pensamento baseado em imagens é que ele refere-se tipicamente a um certo tipo de conteúdo ou assunto, como as propriedades ópticas ou geométricas, ou o que podemos chamar as propriedades de aparência das coisas sobre as quais estamos pensando (Pylyshyn, 2002, pp. 157-8).

Assim, Pylyshyn acredita que os processos por trás das imagens podem muito bem não diferirem dos demais processos mentais: nisso consiste a "hipótese nula". Sua proposta para o formato das representações mentais, por sua vez, envolve um tipo de representação que se assemelha a um tipo de linguagem simbólico-estrutural explorada por Jerry Fodor (1975), e que ficou conhecida como "linguagem do pensamento" ou “mentalês" [mentalese].

\subsection{A contribuição das técnicas de imageamento cerebral}

A partir dos anos 1980, consolidou-se o uso de técnicas não invasivas para a obtenção de imagens espaciais e temporais da atividade cerebral. Os pioneiros das técnicas de medição do escoamento de sangue em pequenas regiões do cérebro foram o sueco David Ingvar e o dinamarquês Niels Lassen, em 1961, que utilizaram marcadores 
radioativos. Pesquisas de diversos grupos levaram o florescimento de duas técnicas principais de imageamento na década de 1980 (Libet, 2004, pp. 21-3).

A primeira é a tomografia de emissão de pósitrons, conhecido como escaneamento PET (PET scan). A atividade cerebral envolve consumo de glicose, então áreas mais ativas têm uma concentração maior dessa substância. Os cientistas preparam uma substância semelhante à glicose, em que há a troca de um radical por um átomo de fluor radioativo, que emite pósitrons (elétrons com carga positiva). Essa molécula se comporta quimicamente como a glicose, mas os pósitrons emitidos logo interagem com elétrons, transformando-se em dois fótons de raio gama, que são emitidos em sentidos opostos. Detectores de raio gama são capazes de registrar esses fótons em coincidência, revelando o local exato de sua emissão.

O segundo desses métodos é o imageamento por ressonância magnética funcional (fMRI). A ressonância magnética é uma técnica complicada que detecta a presença dos núcleos dos átomos. No caso da molécula de hemoglobina, a presença ou ausência de oxigênio altera a resposta magnética, de forma que a fMRI pode distinguir áreas em que o consumo de oxigênio é alto, justamente aquelas em que ocorre atividade cerebral. Esse mecanismo dependente do nível de oxigênio no sangue é conhecido pela sigla BOLD (blood-oxygen-level dependent). A resolução espacial é de em torno de 1 $\mathrm{mm}^{3}$, correspondendo a milhões de neurônios, e a resolução temporal é de alguns segundos.

A desvantagem desses métodos é que a resolução temporal não é muito boa. Para medições que possam distinguir um décimo de segundo, como os necessários nos experimentos de Benjamin Libet, utiliza-se o eletroencefalograma (EEG). Libet chama atenção para o fato de que essas técnicas de imageamento fornecem apenas informação sobre a localização da atividade cerebral, mas não sobre o tipo de atividade das células 
nervosas. Segundo esse autor, "é mesmo possível que as áreas que mostram atividade aumentada não são os sítios de maior importância na iniciação ou organização das funções sendo testadas. Os sítios primários poderiam ser menores e mostrar mudanças muito mais fracas nas imagens medidas" (Libet, 2004, p. 23).

Esses comentários alinham-se com a opinião do próprio Pylyshyn, em sua crítica à defesa por parte de Kosslyn de que tais técnicas das neurociências, por si sós, seriam capazes de solucionar o debate da imagética. Para Pylyshyn (2007), a posição de Kosslyn é muito simplista, pois informação de localização cerebral não basta para se esclarecerem as relações entre atividades cerebrais e funções mentais.

A tese de Kosslyn e colaboradores, confirmada segundo eles por técnicas de imageamento cerebral, é de que áreas do córtex que são organizadas "topograficamente" são ativadas não só na percepção do mundo externo, mas também durante a visualização de imagens, especialmente quando as formas em questão são visualizadas com alta resolução (Kosslyn, Thompson \& Ganis, 2006, p. 130).

Na década de 1980, acumulou-se evidência experimental de que há áreas do cérebro que afiguram padrões visuais de maneira topográfica, ou seja, preservando, de maneira distorcida, a estrutura espacial do estímulo visual presente na retina.

A Fig. 3 é um exemplo do padrão de ativação que ocorre na área visual V1 de macacos rhesus (Macaca mulatta) (discutido por Kosslyn et al., 2006, p. 16). Os defensores do modelo pictorialista acreditaram que estavam diante de evidências experimentais que pudessem, por si, encerrar o debate da imagética a favor da postulação de uma forma pictórica/imagética por trás das imagens mentais. 

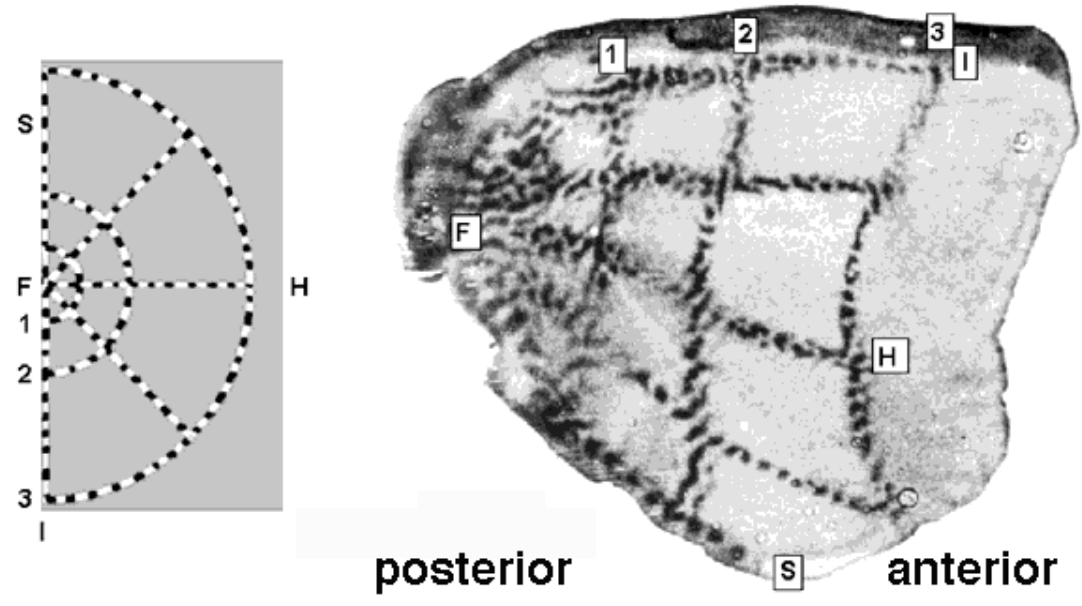

Figura 3: Mapa retinotópico na área visual V1 em macaco rhesus (Tootell et al., 1982).

Porém, tal constatação experimental não se mostra suficiente para corroborar a teoria pictorialista, pois a mera preservação da estrutura topográfica dos estímulos nas áreas do córtex ligadas mais diretamente à retina não explica como essa informação é processada, para dar origem às imagens mentais. E a evidência de que essas áreas são ativadas durante a visualização (interna) de imagens é ainda controvertida. 


\section{Capítulo 2}

\section{A teoria de Kosslyn da representação por imagens}

\subsection{Propriedades privilegiadas das imagens mentais}

Uma forma de Kosslyn referir-se às representações imagéticas na mente é falar em "propriedades privilegiadas das imagens mentais", que dizem respeito às propriedades do espaço, ou seja, distância e ângulo visual. Essas propriedades deixam "rastros" que podem ser mensurados experimentalmente através do tempo de reação ou de escaneamento dos sujeitos. O modelo pictorialista considera que essas propriedades associadas às imagens mentais estão associadas a propriedades análogas do sistema visual primário.

A distância é uma dessas propriedades privilegiadas que Kosslyn identifica na arquitetura imagética, e que somente as afigurações [depictions] possuiriam, não as representações proposicionais. Essa propriedade tem grande importância em toda a organização da imagem e influencia diretamente o tempo de escaneamento.

Mas o que significa afirmar que imagens mentais têm distância? Certamente não se trata da mera afirmação de que imagens na retina levam a projeções em áreas corticais primárias, conservando parte da estrutura topológica. Isso não é motivo de disputa, e há evidências claras disso, como na Fig. 3 (da seção anterior).

A afirmação de que imagens mentais têm espaço consiste da afirmação de que é possível indexar cada ponto da representação mental aos pontos do mundo externo. Após concluir, através de experimentos como o da rotação mental e do escaneamento mental de imagens, que a imagem mental seria uma representação pictórica, Kosslyn 
passou a explorar questões relacionadas ao "tamanho" ou "escala" de uma imagem bidimensional, e à "definição" ou nitidez de uma imagem mental.

Em um de seus experimentos, concluiu que o sujeito pode aumentar o tamanho de uma imagem, de maneira que suas bordas fiquem fora da imagem visualizada. Seria, em outras palavras, como se as pessoas realizassem um "zoom" na imagem mental quando desejassem ver melhor alguma característica. Além disso, quando solicitado para sair de um ponto e ir para este outro ponto fora do campo visual, o tempo gasto foi novamente proporcional à distância entre os pontos (Kosslyn, 1983, p. 48).

Em outro experimento, pediu aos sujeitos para imaginar um animal pequeno, como um coelho, de duas maneiras (Kosslyn, 1975, p. 345). Na primeira situação, deveria ser imaginado ao lado de um elefante, para que ambos estivessem presentes na representação mental, preenchendo-a, e para que o coelho ficasse pequeno. Na segunda situação, o sujeito deveria imaginar apenas o coelho, de perto, ou ao lado de uma mosca, para que fosse imaginado grande. Os sujeitos deveriam então relatar detalhes da imagem do coelho (por exemplo: “ele tem orelhas?"), e o resultado foi de que demorava mais tempo para encontrar os detalhes na imagem menor do que na maior. Os sujeitos chegavam a relatar que pareciam precisar "dar um zoom" na imagem para ver melhor.

No trabalho mais recente de Kosslyn, no qual são incorporadas concepções neurocientíficas, apresenta-se a seguinte explicação:

as conexões inibitórias, em áreas topograficamente organizadas, são tipicamente curtas, e dessa maneira quando muita variação espacial está empacotada em uma região pequena, um input forte é necessário para sobrepujar a inibição (Kosslyn et al., 2006, p. 148).

Vemos assim como Kosslyn incorpora detalhes da neurologia das áreas topograficamente organizadas, argumentando que o poder de resolução do córtex visual limita a quantidade de informação presente em uma imagem pequena. 
As propriedades da arquitetura imagética postuladas por Kosslyn, tais como espaço, resolução e ângulo visual, são características do sistema visual primário que foram transpostas para essa arquitetura, com o objetivo de "externalizar a introspecção" e de realizar medições através de experimentos comportamentais.

Essa proposta de estudar as operações mentais geram problemas metodológicos de interesse para a filosofia da ciência. Conforme já vimos, isso envolveu inicialmente técnicas de medição do tempo de reação, e posteriormente o uso de neuroimagem, em busca de se estudar o que acontece na mente quando estamos introspectivamente conscientes de realizar várias atividades com objetos em nossas imagens mentais.

Segundo Kosslyn (1983, p. 29):

De acordo com a abordagem das ciências cognitivas, uma imagem é uma representação na mente que gera a experiência de "ver" na ausência da estimulação visual apropriada dos olhos. Idealmente, então, gostaríamos de estudar essa representação diretamente. Infelizmente, no entanto, imagética envolve tanto uma representação quanto uma experiência consciente, o que torna as coisas difíceis.

Kosslyn (1983, p. 37) tece considerações sobre esses problemas metodológicos envolvendo a introspecção em relação às imagens mentais. Para o autor, esses relatos não são confiáveis, já que "imagens são privadas e não verbais, e não há como saber se todos nós temos acesso a elas e as interpretamos da mesma forma".

Por conta disso, o autor decidira observar

o tempo que leva para as pessoas usarem imagens de certas maneiras, os tipos de erros realizados quando se utiliza imagens, e a maneira que as imagens afetam certos juízos. Se imagens realmente afiguram, a representação deve ter um "tamanho", "forma" e "orientação" em um espaço funcional (como em um padrão de pontos numa matriz), e essas propriedades devem afetar os tempos de processamento e afins. Por exemplo, essas propriedades devem estar refletidas no tempo que leva para alguém escanear uma imagem, rodá-la e assim por diante (Kosslyn, 1983, p. 38). 
$\mathrm{O}$ autor pretende com essa abordagem, atrelar a imagética a algo de que a ciência atual tem conhecimento melhor, que é o processamento visual primário, procurando mostrar que as propriedades envolvidas nesse estágio de processamento mais automático, que não envolve consciência, estão presentes nos processos mais profundos envolvendo imagens mentais.

\subsection{O problema da representação interna}

A questão precedente leva ao problema da representação mental "mais interna", para o qual Kosslyn propõe uma solução que considera condizente com a concepção pictórica da representação mental. Ele propõe três tipos de estruturas que interagem para gerar uma representação: as representações de superfície, as representações profundas e o processador que opera as relações entre as representações profundas e as de superfície, o chamado "olho da mente".

A expressão "representação mais interna" origina-se nos modelos da inteligência artificial das décadas de 1950 e 60 (ver seção 1.1), remetendo a estruturas típicas da linguagem computacional. Lembremos que tanto o modelo de Kosslyn quanto o descritivista de Pylyshyn inspiraram-se no entusiasmo com a inteligência artificial, e portanto dialogavam com essas linguagens teóricas computacionais. No modelo pictorialista de Kosslyn, se temos experiências imagéticas, porque não pensar que elas surgem de imagens materiais reais existentes no cérebro, e passíveis de computações, rotações, translações, etc.?

As evidências advindas dos avanços em técnicas em imageamento no cérebro nos anos 90, por sua vez, parecem ter levado Kosslyn a uma mudança de opinião a 
respeito de se o display interno é literal, passando a propor um tipo de representação que não precisa parecer espacial, o que modifica completamente a sua abordagem.

Isso transparece na seguinte nota de rodapé:

$\mathrm{O}$ fato de que áreas topograficamente organizadas sejam fisicamente pictoriais [depictive] é irrelevante para propósitos atuais. Os neurônios nessas áreas poderiam estar arbitrariamente interconectados, mas contanto que conexões fixas para áreas subsequentes "desembaralhassem" apropriadamente a atividade em áreas anteriores, as áreas anteriores serão funcionalmente pictoriais [will functionally depict] (Kosslyn et al., 2006, p. 131).

Trata-se aqui de uma concessão radical na visão de Kosslyn, pois elimina o cerne da "teoria da afiguração", que foi objeto de crítica por Pylyshyn e outros no debate da imagética, ou seja, a postulação de que as imagens mentais têm propriedades privilegiadas como distância, ângulo visual e até mesmo "escala".

O modelo pictórico de Stephen Kosslyn tem forte influência da definição de representação de David Marr (1982), segundo a qual "diferentes formatos (de representação interna) tornam diferentes informações explícitas e acessíveis" (Kosslyn et al., 2006, p. 8). Dessa maneira, uma representação pode ser compreendida como "um tipo de código, uma forma de especificar informação" (Kosslyn, 1994, p. 4).

É interessante que Pylyshyn (2007, p. ix) também reconhece a influência de Marr, em especial quanto ao "princípio das restrições naturais", que Pylyshyn aplica para a capacidade que um indivíduo tem de selecionar coisas em seu campo visual, e de reidentificá-lo em diferentes contextos, mesmo diante da mudança de várias de suas propriedades.

Voltando a Kosslyn, como se dá a especificação da informação numa representação mental? Para responder a esta questão, é preciso refletir, em primeiro lugar, sobre o que torna uma imagem pictórica.

Ainda baseado nos trabalhos de Marr, Kosslyn propôs que 
as propriedades das representações são necessariamente definidas no contexto de um sistema de processamento, o que inclui tanto as representações quanto processos que podem interpretá-las e manipulá-las (Kosslyn, 1994, p. 4).

É importante compreender esse aspecto da relação da representação do sistema, devido ao aspecto espacial funcional que o autor propõe em seu modelo.

O que se pretende com essa expressão pode tornar-se mais claro se pensarmos que "uma representação pictórica é um tipo de figura que especifica as localizações e valores de configurações de pontos no espaço" (Kosslyn, 1994, p. 5), tal como propõe o autor.

Para nos dar uma ideia mais clara de como se daria essa representação, Kosslyn pede para que tenhamos em mente um modelo de um tubo de raios catódicos acoplado a uma tela de computador, no qual imagens são geradas a partir de informação simbólica que está armazenada na memória da máquina. A figura na tela tem aparência espacial, mas ela é gerada pela representação que está na memória, armazenada em um "espaço funcional", um espaço no qual há uma ativação da informação necessária para geração da imagem.

O espaço no qual os pontos aparecem não precisa ser físico, tal como esta página, mas pode ser como uma matriz [array] num computador, que especifica relações espaciais de maneira meramente funcional. Ou seja, as localizações físicas no computador de cada ponto de uma matriz não estão elas mesmas ordenadas em uma matriz; é somente em virtude de como essa informação é "lida" e processada que ela passa a funcionar como se fosse ordenada numa matriz (Kosslyn, 1994, p. 5).

As "informações da memória" no modelo pictorialista são traduzidas no que o autor denomina "representações profundas", que correspondem a estruturas simbólicas mais abstratas armazenadas na memória de longo prazo. As imagens formadas na tela (na analogia computacional), por sua vez, consistem de "representações de superfície". 
Aqui torna-se clara a influência do modelo de Marr nos trabalhos do autor. É somente através de um processo de leitura e interpretação no contexto do espaço funcional que a imagem passa a existir.

Kosslyn postula também, para levar adiante essa função de processamento dentro do cérebro, um "observador interno" ou "olho da mente". Ou seja, as representações imagéticas são formadas a partir das representações profundas, a partir de um processo de interpretação por parte do olho da mente.

Kosslyn denomina as experiências que temos quando utilizamos imagens mentais (para resolver problemas que envolvem raciocínio espacial, ao extrair informações de rememorações) de "experiências de ver com os olhos da mente". A própria delineação de "experiência subjetiva" tem sido considerada um conceito problemático na filosofia da mente, cunhando-se a terminologia de qualia numa tentativa de nivelar o vocabulário filosófico e nas neurociências sobre o assunto, mas ao que parece, o termo continua gerando controvérsias. Kosslyn nos deixa numa situação mais delicada ao relacionar essa noção já controversa com a metáfora de "ver com os olhos da mente".

Mas afinal, ter uma representação de forma imagética na mente significa postular uma visualização interna das imagens? Kosslyn acredita que não.

O autor define "olho da mente" de maneira mais geral, como um "processo de interpretação pictórica”, uma função necessária ao processamento das imagens internas. (Kosslyn et al., 2006, p. 40):

Podemos pensar no olho da mente como um processador que interpreta representações pictóricas (as quais por sua vez - de alguma forma - em última análise produzem as experiências perceptivas visuais).

Além disso, de acordo com o modelo de Kosslyn, quando esses processos interpretativos são aplicados às informações perceptuais trazidas da memória, têm-se 
imagens mentais, e quando é aplicado à informação presente através dos sentidos, temse um "percepto". O autor deriva dos trabalhos de Marr (1982) essa noção de funções cognitivas serem compreendidas em termos de processos que criam e interpretam representações.

Percebemos o peso desse conceito, na teoria sobre a mente de Kosslyn, quando consideramos o objetivo do autor de mostrar que imagens mentais e percepção têm propriedades semelhantes. Isso porque se as representações mentais de fato tiverem um formato distinto (pictórico), então um tipo diferente de sistema de processamento se mostra necessário para a interpretação das mesmas. Nas palavras do autor:

dada a existência de representações com propriedades funcionais particulares, existem restrições na natureza possível dos processos no sistema. Os procedimentos interpretativos que operam em representações pictóricas são bastante diferentes dos procedimentos que interpretam strings linguísticos (Kosslyn et al., 2006, p. 53).

Kosslyn não pretende a partir dessa noção, no entanto, postular uma figura literalmente projetada no córtex visual. "Ao invés disso, representações são padrões de ativação neural que, por sua vez, afetam outros padrões de ativação no sistema de processamento" (Kosslyn et al., 2006, p. 68).

Pylyshyn, a esse respeito, busca contestar que o apelo a um espaço funcional tenha validade, tratando-se de uma forma vazia de sentido (para além da interpretação trivial de que imagens estão dispostas num espaço físico), e "meramente recoloca os fenômenos que estamos tentando explicar” (Pylyshyn, 2003, p. 360). 


\subsection{A relação representacional}

Quando se diz que imagens são "pictoriais" (depictive), no modelo pictorialista, isso implica a existência de uma certa relação representacional entre imagens mentais e o mundo. A natureza dessa relação seria de afiguração, ou seja, a imagem tem semelhança espacial e estrutural com aquilo de que é imagem, não se tratando de uma relação simbólica, semântica. A representação, assim, "mostra" por semelhança ao objeto representado, através da correspondência de partes da representação a partes do objeto (Kosslyn, 1994, p. 5); ou seja, o significado nesse tipo de relação representacional se dá através de um espelhamento entre realidade e representação.

A representação por semelhança encontra-se em diversas passagens na história de filosofia, tais como na obra de Hume, como um dos princípios de associação (juntamente com a contiguidade e a causalidade). Mas ela certamente não se aplica às representações simbólicas, e mesmo quando há semelhança, esta não pode ser o que determina o significado ou a referência (Pylyshyn 2007, p. 126).

O modelo pictorialista, na história da filosofia, ficou conhecido como "teoria da afiguração", cuja versão mais acabada foi desenvolvida por Ludwig Wittgenstein, em sua primeira filosofia, no Tractatus Lógico-Filosófico (Wittgenstein, 1993), originalmente de 1921. Segundo sua teoria, a formação do sentido sentencial se dava a partir de combinações do significado de nomes em proposições atômicas, e esses nomes eram tidos como referentes de objetos simples num mundo lógico do qual a própria linguagem atuava como espelho. Posteriormente, em sua filosofia tardia, nas Investigações Filosóficas, publicado postumamente em 1953 (Wittgenstein, 1994), o mesmo autor desenvolveu uma severa crítica dessa teoria afiguradora da linguagem, que 
tinha como um dos focos uma busca por essências na forma da análise lógica das proposições.

A crítica à teoria da afiguração na obra de um autor complexo como Wittgenstein é um tópico extenso, que não poderemos tratar aqui. O que faremos agora é explorar aspectos da versão da teoria da afiguração assumida pelo modelo pictorialista de Stephen Kosslyn.

O problema da imagética foi colocado da seguinte maneira por Kosslyn:

Imagens mentais, sendo mentais, não são figuras reais [actual pictures] com tamanho, peso e assim por diante; nem são tais imagens vistas com um olho real. Mas, se elas não são imagens reais, que tipo de figuras elas são? Como pode existir uma figura na mente? (Kosslyn, 1983, p. 20)

No debate sobre imagética, quer se adote uma posição pictorialista ou proposicionalista, há um grande interesse em definir a natureza das imagens, no sentido de compreensão do que torna uma imagem pictórica, devido à necessidade de se utilizar as representações (pictóricas ou proposicionais) em modelos computacionais de processamento de informação.

Pylyshyn (2007, p. 156) questiona, por exemplo, a respeito de imagens mentais terem propriedades espaciais, se existe algum sentido em tal afirmação diferente da interpretação literal de que imagens estejam dispostas numa superfície física.

O programa de pesquisa de Kosslyn dá ênfase à natureza dos eventos internos que estão por trás da experiência imagética, os quais o autor intitula de "experiência de ver com os olhos da mente" (Kosslyn, 1994, p. 3), e não às qualidades da experiência em si.

Num de seus escritos mais recentes, Kosslyn define imagens mentais como sendo "quase pictóricas" (quasi-pictures). Imagens mentais não são realmente vistas. Além disso, o fato de que se parecem com os objetos representados não é, em si, 
evidência a favor da teoria da afiguração, como discutimos acima, com referência a Wittgenstein.

Antes de considerar o problema da forma representacional, talvez seja importante observar a própria definição por parte do autor do termo "imagem mental":

em nosso uso dessa expressão, uma imagem mental ocorre quando uma representação do tipo criada durante as fases iniciais da percepção está presente, mas o estímulo não está mais sendo percebido; essas representações preservam as propriedades perceptíveis do estímulo e em última análise geram a experiência subjetiva da percepção. (Kosslyn et al. 2006, p. 4)

Ou, de maneira mais clara: "Imagem é uma representação na mente que dá origem à experiência de 'ver' na ausência da estimulação visual adequada aos olhos" (Kosslyn, 1983, p. 29). Kosslyn deixa clara, através dessa definição, a intenção de ligar as propriedades da percepção visual primária às imagens mentais.

A característica mais marcante de uma representação pictórica está no fato de que, tal como uma figura, incorpora espaço daquilo que é representado. Segundo Kosslyn, "há boas evidências de que o cérebro afigura [depicts] representações literalmente, utilizando espaço no córtex para representar espaço no mundo.”

À primeira vista, parece tratar-se da observação trivial sobre a própria existência de áreas topograficamente organizadas no cérebro, conjuntamente a uma explicação de sua atuação funcional.

Um exame da obra do autor, inclusive atentando-se aos movimentos de sua pesquisa desde os experimentos iniciais que o motivaram no início dos anos 1970, nos mostra que há um modelo informacional/computacional norteador de seus escritos. Isso vale também em sua última fase, quando o autor busca, utilizando-se de novas técnicas de imageamento do cérebro, tais como fMRI e PET, buscou uma identificação de áreas cerebrais ativadas a entidades postuladas anteriormente em sua teoria. 
Com isso, a ideia de Kosslyn é mostrar que imagética e percepção estariam ligadas em seus mecanismos (como nos mecanismos por trás da definição visual de objetos). Conclui que se esses mecanismos estiverem também "por trás das imagens, então é possível se basear na riqueza de conhecimentos sobre a percepção, as suas propriedades computacionais e o seu substrato neural para teorizar sobre a imagética" (Kosslyn, 1994, p. 22).

Quando se fala em propriedades de imagens mentais, é preciso no entanto esclarecer quais dessas propriedades das imagens reais são relevantes. Grande parte do debate sobre imagética, na verdade, gira em torno dessa questão.

Segundo Kosslyn, as nossas experiências imagéticas (como ao fecharmos os olhos e imaginarmos o mapa da Fig. 2) devem-se a uma forma cuja arquitetura teria natureza também imagética. A definição da forma imagética no contexto da teoria pictorialista de Stephen Kosslyn especifica uma estrutura espacial bidimensional que é o lugar das imagens no cérebro, mas que ao mesmo tempo, tal como acontece em telas de computadores, só existe à medida que é gerada a partir de informações online da memória.

Imagens mentais, assim, mapeariam espaço no cérebro a espaço nos objetos, tal como uma imagem real incorpora características espaciais do objeto representado. Pode-se compreender "imagem real" em oposição a "imagem mental", simplesmente como uma representação qualquer de objeto na qual observa-se a relação de semelhança entre partes do objeto representado e partes da representação, tal como numa fotografia, desenho figurativo ou representação retiniana. 


\subsection{A analogia computacional no modelo pictorialista}

O modelo pictorialista é fortemente inspirado numa analogia entre como os computadores processam informação e a mente humana (Kosslyn, 1983, p. 13). Pode-se explicar o funcionamento dos computadores ao nível físico (como uma corrente elétrica é transmitida de um ponto a outro) ou ao nível funcional, em termos de como signos são utilizados para resolver problemas.

O nível funcional de analise é utilizado, dependendo da natureza das questões para um dado assunto. Por exemplo, a explicação de porque um parafuso em particular não se encaixa num determinado buraco não será dada em termos de física subatômica.

Kosslyn (1983, p. 20) acredita ainda que uma boa maneira de se estudar a mente é tentar descobrir como construir um programa de computador que a imite, e essa intuição é inspiradora para as questões propostas por seu programa de pesquisa, já que lança a questão sobre o que faz com que uma representação seja pictórica e de que maneira essa representação atua no processamento de informação, dado um certo programa computacional real que tenha sido desenvolvido para esse fim. Para Kosslyn, "se for possível programar um computador para operar a maneira que acreditamos que nós humanos operamos, então haveria um meio de testar a teoria".

Por outro lado, "a visão do cérebro-como-computador sugere uma maneira de salvar a metáfora da afiguração sem que se fique preso aos absurdos óbvios de uma interpretação literal” (Kosslyn, 1983, pp. 20-1). O absurdo a que Kosslyn se refere está no sentido de postular uma figura simplesmente projetada na área V1, sem referência a uma geração de imagens num espaço funcional.

Tendo isso em mente, Kosslyn se vale da analogia entre imagens mentais e imagens na tela de um monitor de um computador gerado a partir de um tubo de raios 
catódicos, mencionado na seção 2.2, e que persiste mesmo nas reformulações de sua teoria. As imagens na tela surgem a partir de uma ativação do espaço funcional da memória do computador, e algo análogo ocorreria no cérebro humano, fugindo assim ao absurdo de uma interpretação literal da analogia entre imagens mentais e imagens em telas.

Tal analogia evita também os problemas de uma interpretação literal de imagens sendo projetadas numa superfície no cérebro. Aqui, devemos evitar uma confusão semântica do verbo "projetar", que tem diferentes acepções. Na neurociência, uma "projeção" geralmente se refere à extensão de fibras nervosas de uma região para outra, como quando se fala na projeção de uma fibra $\mathrm{C}$ de uma região na pele até as áreas da dor no cérebro.

A intenção de Kosslyn, a esse respeito, consiste de que o espaço funcional realize uma projeção através de uma ativação das informações a partir das "representações profundas", tal como o computador gera imagens numa tela a partir de informação que não tem, em si, caráter imagético. Mesmo assim, "dados que estão armazenados como símbolos na memória do computador emergem na tela em forma pictórica" (Kosslyn, 1983, p. 21).

Esse modelo de representação está intimamente relacionado a uma intuição do autor, segundo a qual algo não precisa ser uma figura para funcionar como tal. Surge assim o modelo da "matriz mental", que escapa aos embaraços de assumir a existência de figuras reais no interior do cérebro, apesar de haver uma organização retinotópica em áreas mais próximas da retina, como mostrado na Fig. 3).

Kosslyn (1983, p. 22) caracteriza o conceito de matriz da seguinte maneira:

Se você olhar de perto uma tela de televisão, você pode ver que as figuras formadas são, na verdade, arranjos de pontos (conjuntos). Podemos pensar na tela vazia como uma matriz formada por centenas de linhas horizontais e verticais que formam pequenos quadrados ou células através da superfície. Quando pontos são 
colocados em certas células, o resultado é uma figura. Esse padrão é claramente pictórico [...] porque tem características espaciais - distâncias entre pontos, relações geométricas [...] o que permite que o espaço na matriz corresponda a espaço real e pontos na matriz correspondam a pontos na superfície dos objetos.

A importância para a tese pictorialista de se utilizar de um modelo matricial, devemos notar, está em que as características espaciais que são preservadas na imagem não precisam estar representadas numa figura real. O lugar das representações na mente, assim, deixa de ser, em parte, interpretado de maneira pictórica, já que as representações são geradas quando se dá uma ativação a partir de informação das representações profundas.

Tratando-se de um conceito de difícil compreensão e visualização, Kosslyn utiliza-se de exemplos na tentativa de ilustrar o conceito de representação através de um espaço funcional. Segundo o autor, uma informação pode ser "armazenada" até mesmo por um grupo de pessoas se interpretada da maneira correta. Suponha, por exemplo, que você mostre a um certo número de pessoas uma figura desenhada numa matriz 6 x 6 (Kosslyn, 1983, p. 22). Pede-se então, que cada pessoa memorize o conteúdo de uma célula diferente da matriz. "Depois que cada célula tiver sido memorizada, a figura terá sido destruída, mas as pessoas coletivamente armazenam a informação espacial que estava na figura."

Para que se tenha uma ativação da figura, basta nomear as células desejadas. Importante notar que "embora as pessoas possam estar em qualquer lugar, elas funcionam para representar pontos que estão juntos na matriz [...]. Toda a informação na figura está disponível, mesmo que não exista uma figura real” (Kosslyn, 1983, p. 23). Da mesma forma, no computador não existe uma matriz física, disposta espacialmente em 6 fileiras de 6 colunas, mas há uma interpretação que faz com que esses elementos funcionem como se estivessem arranjados dessa maneira. 
Essa analogia com o funcionamento dos computadores pode ser usada para interpretar os importantes experimentos de escaneamento mental de imagens, que fornecem um forte argumento favor da teoria imagética. Afinal, o computador realiza um "escaneamento" através das células em qualquer direção, descobrindo quais estão próximas umas das outras e realizando uma categorização dessa informação, e isso só é possível porque os pontos são tratados como se estivessem fisicamente arranjados. Kosslyn generaliza a partir de células na memória do computador para arranjos de neurônios no cérebro que possam corresponder, na representação, a partes do objeto representado: "Dessa maneira, células nervosas podem funcionar como se estivessem agrupadas como uma tela de televisão sem que sejam uma tela" (Kosslyn, 1983, p. 25).

Com essa abordagem às representações pictóricas, Kosslyn pretende mesmo ter dissolvido o "aparente paradoxo do olho da mente". O olho da mente torna-se, aqui, um processador que interpreta a tela [display] visual.

"Sabemos como fato que computadores trabalham sem pequenos homens dentro de suas cabeças. Adeus homúnculo!" (Kosslyn, 1983, p. 25).

Segundo críticos dessa posição, no entanto, o problema do homúnculo não trata da existência de pequenas entidades na mente, e sim da confusão conceitual de transpor telas externas para telas [displays] internas. Creio que Kosslyn não dá resposta adequada a este problema, como examinarei mais adiante.

\section{$2.5 \mathrm{O}$ espaço funcional}

Conforme já vimos, Kosslyn pretende caracterizar imagens mentais através de propriedades do sistema visual primário, como resolução, ângulo visual e a 
incorporação de espaço, no que o autor define como "espaço funcional" da representação imagética. Não se trata de uma representação afigurativa [depictive representation] literal, como seria uma fotografia comum, mas uma representação afigurativa funcional (Kosslyn et al., 2006, p. 12).

Essa caracterização é importante, porque o espaço funcional traz em si aspectos comuns a figuras. Mas apesar de esta concepção pictorialista ter sido bastante explicitada pelo autor, ao longo de anos de publicações, tratando-se do maior corpo de teoria sobre imagética, ela ainda continua sendo difícil de entender, como coloca Tye (1991). O próprio Kosslyn (1994, p. 3) admite que a noção de imagem mental é "notoriamente ambígua" e passível de mais de uma faceta de definição.

Kosslyn e colaboradores reiteram que a informação profunda que gera uma imagem mental pode não estar ordenada topograficamente da usual maneira espacial, mas sim organizada em um espaço funcional:

Como foi visto na analogia computacional descrita acima, não é necessário que haja uma figura real no cérebro para que se tenha uma afiguração: tudo o que é preciso é um "espaço funcional" no qual distâncias possam ser definidas conforme a informação é processada. (Kosslyn et al., 2006, pp. 14-5)

Segundo Kosslyn, existe uma correspondência entre partes e relações espaciais da representação e do objeto. Esse "mapeamento estrutural, que confere um tipo de afiguração, está por trás da forma como imagens transmitem conteúdo específico" (Kosslyn et al., 2006, p. 44).

Imagens mentais, assim, incorporam características espaciais através de uma ativação da informação armazenada nas representações "mais abstratas" e que geram imagens (representações de superfície) quando necessário. Segundo Kosslyn, é impossível explicar o conceito de imagem sem que se dê uma explicação simultânea desse espaço no qual as imagens são projetadas. Para esclarecer esta afirmação, 
consideremos novamente o exemplo da tela de computador, dado pelo autor para o modelo de espaço funcional.

A metáfora da tela [display] de computador sugere algumas possibilidades sobre como o sistema de armazenamento e retenção da imagem poderia funcionar. Se a imagem ela própria é como uma figura de televisão, uma matriz funcional com pontos em diferentes células afigurando alguma coisa, talvez o que é armazenado seja outra matriz, uma espécie de plano mais abaixo sobre o qual cada ponto irá. Se isso for verdade, então tudo o que precisamos fazer para formar uma imagem é ativar a segunda matriz (Kosslyn, 1983, p. 93).

Assim, fica claro que o espaço funcional não é, para Kosslyn, necessariamente um display físico. Trata-se de uma estrutura semelhante à registrada na memória de um computador, permitindo, a partir da definição de registros e operações, que a atividade possa estar espalhada na memória. Isso é vantajoso no sentido de que a informação não precisa, a despeito de tratar-se de uma representação pictórica, estar no mesmo lugar, tal como seria necessário numa figura disposta espacialmente.

Segundo Pylyshyn (2003, p. 360), essa é uma tentativa de tornar o modelo pictorialista mais atraente, já que "aparentemente permite afirmar que as imagens são espaciais sem nos comprometer em afirmar que elas são colocadas num espaço real no cérebro ou em outro espaço físico."

Uma crítica ao recurso a um espaço funcional é feito por Dennett (1991), em sua crítica ao modelo pictorialista. Esse autor compreende o espaço funcional como um espaço fenomênico, até mesmo como um "espaço lógico":

Esse é um espaço sobre o qual nada é literalmente projetado; as suas propriedades são simplesmente constituídas pelas crenças do sujeito (heterofenomenológico). [...] A representação de espaço no cérebro nem sempre usa espaço-no-cérebro para representar espaço, e a representação de tempo no cérebro nem sempre usa tempo-no-cérebro (Dennett, 1991, p. 131),

Dennett pretende com isso questionar a validade e usos do conceito de espaço funcional: afinal, de que se trata essa afirmação? De uma espécie de "espaço 
fenomênico", para dispor fenômenos conscientes tais como experiências imagéticas? Ou trata-se de uma espécie de "espaço lógico"? À maneira wittgensteineana de argumentar, Dennett busca uma limpeza conceitual de nossas falsas intuições a partir de teses da psicologia do senso comum presentes em teorias sobre a mente. Para esse autor, o "espaço funcional" consiste de uma dessas confusões conceituais originadas da intuição de que a experiência imagética é muito semelhante à experiência da visão.

O fato de não haver uma projeção real a partir do conceito de espaço funcional, não consiste, portanto, para Dennett, numa vantagem explicativa do modelo de Kosslyn. Pylyshyn aponta um problema semelhante ao apontado por Dennett em sua crítica à noção de espaço funcional. Segundo esse autor:

O problema com a proposta do espaço funcional é que espaços funcionais não têm, intrinsecamente, quaisquer propriedades particulares. Sendo funcionais, eles não estão sujeitos a leis naturais e portanto pode-se supor que eles têm quaisquer propriedades necessárias para dar conta dos dados experimentais. Dado que um espaço funcional não tem propriedades intrínsecas, quaisquer propriedades que tenham são estipuladas ou supostas extrinsecamente, podendo assim acomodar quaisquer achados que se queira (Pylyshyn, 2003, p. 360).

Para Pylyshyn, através da noção de espaço funcional, Kosslyn abre caminho para um tipo de explicação para as representações subjacentes às imagens mentais que supõe qualquer forma de representação, indo na direção da "hipótese nula" proposta por Pylyshyn (2002), e que apresentamos na seção 1.3.

Assim como no caso do espaço funcional do modelo pictorialista de Kosslyn, não há uma projeção real. No entanto, em Dennett não há a ênfase numa abordagem computacional de fundo. 


\section{Capítulo 3}

\section{A Crítica de Pylyshyn à Teoria da Afiguração}

\subsection{Crítica ao panorama interno e ao olho da mente}

Há na literatura várias afirmações de um pensamento feito com imagens. Um exemplo marcante aparece no relato de Temple Grandin (1996), possuidora de síndrome de Asperger, e mencionada no livro Um antropólogo em marte, de Oliver Sacks (1995). Mas no que consistiria este tipo de pensamento?

Uma concepção comum é representada na Fig. 4, que postula um panorama interno por trás da experiência das imagens mentais. Pylyshyn busca, tal como Dennett, descobrir porque essa "história permanece tão enraizada no pensamento sobre a mente" (Pylyshyn, 2007, p. 121). O que leva tantas pessoas a sucumbir a essa estória de retratos internos (picture story)?

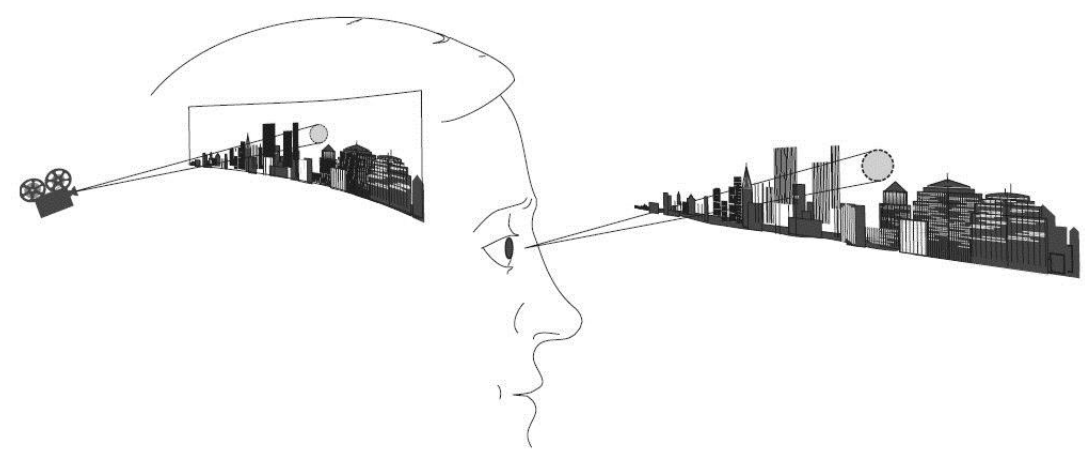

Figura 4: Concepção segundo a qual as imagens internas são projetadas em uma tela interna (picture story), como em um panorama interno (Pylyshyn, 2007, p. 121). 
A resposta a essa questão, para Pylyshyn, está que as pessoas têm uma tendência a atribuir o conteúdo da experiência a certas propriedades intrínsecas de uma representação. Em primeiro lugar, supõe-se que "o conteúdo da experiência reflete o conteúdo de alguma representação mental que desempenha um papel no processo de percepção e imaginação". Em segundo lugar, supõe-se que "o conteúdo dos pensamentos ou imaginações revela a estrutura e propriedades do formato ou meio no cérebro no qual a representação mental é expressa" (Pylyshyn, 2007, p. 121).

A primeira falácia apontada é a suposta equivalência entre conteúdos da experiência e conteúdos dos estados mentais, ou seja, supor de antemão que os estados mentais são imagéticos. O segundo erro, a identificação do conteúdo das experiências imagéticas diretamente com estruturas do meio cerebral, é conhecida na filosofia da mente como "falácia intencional": a falácia na qual se atribui propriedades daquilo que é representado à própria representação (como se a representação da cor vermelha fosse ela própria vermelha).

A correta análise da questão da representação mental não é tarefa fácil, e é preciso levar em conta a possibilidade de uma representação não conceitual do espaço. De qualquer maneira, há diferenças qualitativas entre percepção visual e imagens mentais, conforme apontadas em estudo de Dalla Barba, Rosenthal \& Visetti (2002), tal como quando temos uma percepção vívida que não parece tão real ou o contrário, quanto temos uma experiência vaga que parece mais real do que aconteceu (Pylyshyn, 2007, p. 123).

Segundo nos relembra Pylyshyn (2007, p. 120), existe um abismo [gap] entre nossa experiência visual, que tende a ser contínua e estável, e a informação visual disponível ao cérebro, que é descontínua devido ao estreito campo visual associado à restrita área de alta definição na retina (a fóvea) e aos movimentos sacádicos dos olhos. 
Para Pylyshyn, resolver esse problema - do abismo entre experiência imagética e dados sensórios empobrecidos - postulando um panorama interno equivale ao erro que incorreu Kepler e seus contemporâneos, que procuraram por um lugar no cérebro onde a imagem invertida da retina fosse desinvertida. Assim também,

muitos cientistas da visão procuraram um lugar no cérebro onde os fragmentos da informação visual incidente fosse completada ou preenchida. A experiência da percepção visual sugere que a visão forneceria uma densa estrutura de informação panorâmica, e assim os teóricos vem buscando onde tal representação detalhada poderia ocorrer no cérebro. A resposta é em lugar nenhum (Pylyshyn, 2007, p. 121).

Para resolver o problema do abismo entre experiência imagética e dados sensórios descontínuos, postula-se que a informação processada pelo sistema visual não vem somente da retina (ou da fóvea), mas também de alguma forma de armazenamento visual. O problema é qual a natureza dessa informação armazenada. A teoria tradicional é que a imagem interna é construída através de uma superposição da informação obtida pelos olhares rápidos em diferentes direções, sendo que tal superposição é de alguma maneira projetada em uma tela interna de referência, o panorama, pintando a cena maior para que o "olho da mente" a observe. Ou seja, a teoria da superposição é uma versão da teoria do panorama, pois requer que uma sequencia de imagens retinianas sejam superimpostas para formar o panorama estável. Novos estudos experimentais, porém, trouxeram dificuldades para a concepção da superposição, e mostrou-se que pouca informação é retida de um lance de olhar para outro, ou seja, não há formação de um panorama (Pylyshyn, 2003, p. 16-18).

Os ataques de Zenon Pylyshyn contra a concepção da imagética mental, e a teoria da afiguração nela implícita, se iniciaram em 1993. Em texto mais recente, fez um resumo de seu objeto de ataque: 
Recentemente, tem havido afirmações fortes de que as evidências da neurociência dão base para o que de outra maneira seria uma proposta grotesca; a ideia de que ter uma imagem mental é projetar figuras de duas dimensões em movimento na superfície do nosso córtex visual. (Pylyshyn, 2003, p. 114).

Um dos pontos centrais em sua crítica à posição imagética é a incoerência de supor que imagens na mente precisariam da postulação de um "olho mental", que pudesse observar as imagens internas, ainda mais porque isso sugere a existência de um observador interno, ou "homúnculo":

Por exemplo, algumas das evidências psicofísicas que são citadas como base de uma teoria da afiguração das imagens mentais sugerem uma similaridade entre o "olho da mente" e o olho real que é tão impressionante, que deveria causar embaraço às teorias da afiguração. Não somente sugere que o sistema visual está envolvido em imagética e que examina uma tela pictórica, mas aparentemente atribui ao "olho da mente" muitas das propriedades dos nossos próprios olhos (Pylyshyn, 2002, p. 178).

Além disso, faz-se necessário postular uma superfície na qual a imagem será formada ou projetada, uma espécie de tela pictórica cerebral. Pylyshyn denomina essa equação que conjuga olho da mente, tela para projeção de imagens, e imagens mentais, implícita no modelo imagético, de teoria da afiguração das imagens ou simplesmente teoria da afiguração.

Está claro que, para Pylyshyn, a atribuição de propriedades do olho real ou da visão primária para uma espécie de "olho da mente" é problemática, envolvendo uma confusão conceitual. Assim, não faz sentido simplesmente falar em "ângulo visual mental", como faz Kosslyn, nem em tamanho espacial da imagem mental, e muito menos na definição da imagem mental, como se fosse possível dar um "zoom" para observar uma imagem na mente, tal como fazemos com os olhos. Afinal, que sentido poderia ter a frase "observar com a mente"? Aí está o cerne das críticas de Pylyshyn a esse tipo de transposição de propriedades ópticas para a imagética. 
Pylyshyn (2003) realiza uma espécie de destilação conceitual a respeito de teorias da visão em sua obra Seeing and visualizing is not what you think (Ver e visualizer não é o que você pensa), salientando que "o que vemos é drasticamente condicionado por nossas crenças e expectativas” (Pylyshyn, 2003, p. 49).

Essa visão teve início na psicologia da percepção com o neokantismo do séc. XIX, especialmente em Hermann Helmholtz. No séc. XIX, ela ressurge com o renascimento da psicologia cognitiva, com a publicação do influente artigo dos psicólogos Jerome Bruner e Cecile Goodman (1947), intitulado "Valor e necessidade como fatores organizadores na percepção". Esse artigo tornou-se precursor de um movimento da psicologia que tem influência ainda nos dias de hoje, mesmo na inteligência artificial, e que mostra que percebemos o mundo em categorias perceptuais.

“Não há tal coisa como uma aparência 'crua' ou como um 'olho inocente': nós vemos algo como uma cadeira ou uma mesa ou um rosto ou uma pessoa em particular e assim por diante” (Pylyshyn, 2003, p. 53). Há uma modularidade na visão, com uma distinção entre o tipo de identificação realizada pela visão primária ("ver") e pelos estágios posteriores, que envolvem raciocício ("ver como"). Isso irá levar à distinção qualitativa entre percepção visual e imagem mental.

\subsection{Linguagem do pensamento e experiência imagética}

A teoria da codificação dual (dual-coding theory) foi explicitada por Allan Paivio (1971), e defende que não há outro tipo de representação mental a não ser na forma de palavras ou de imagens. Uma pessoa pode aumentar seu conhecimento de duas maneiras: ou por associações verbais ou por imagens mentais. As informações verbal e 
visual são processadas no cérebro por vias diferentes, e nossas respostas verbais podem ser mediadas tanto por "figuras mentais" quanto por "palavras mentais", como se essas categorias exaurissem as possibilidades de representações mentais.

Pylyshyn (1973, p. 429) aponta, no entanto, problemas com esta concepção. Afora o fato de que podemos ter também pensar auditivos, táteis, etc., a doutrina da codificação dual ignora a possibilidade de uma forma de pensamento inacessível à consciência, e que poderia explicar a criatividade não-verbal sem ter que recorrer à imagética visual.

A tese da linguagem do pensamento, ou interlingua, proposta por Pylyshyn (1973) e Fodor (1975), consiste da postulação de um tipo de representação que não é nem pictórica, nem linguística, de tal maneira que seja necessária uma tradução tanto do formato pictórico quanto do simbólico-estrutural para essa outra linguagem, de natureza mais abstrata. Além disso, justamente por ter um caráter mais abstrato, aspecto importante dessa linguagem é que seria inacessível à experiência subjetiva.

Em seu artigo seminal, Pylyshyn (1973), salienta também que as estruturas por trás das imagens mentais e da linguagem proposicional ordinária também deve ter uma forma conceitual ou proposicional (e não pictórica ou sensória). Tais estruturas seriam descrições simbólicas que seguem uma sintaxe lógica.

Para Pylyshyn, essas são características essenciais num tipo de representação que pudesse atuar como a "forma" dos pensamentos, dadas as críticas constantes do autor a uma confusão por parte do modelo de Kosslyn entre a experiência consciente das imagens e o formato das representações, entre o espaço do mundo em um "espaço interno". Ou seja, não é porque parece para mim que vejo um triângulo, quando resolvo um problema matemático, que é possível mapear o triângulo de maneira causal a um mundo externo ou preencher uma representação de triângulo com inputs de dentro. 
Conforme já vimos, o programa de pesquisa pictorialista procura explicar as experiências de ter uma imagem mental por referência a propriedades privilegiadas de uma arquitetura também imagética no córtex. Mais especificamente, defende que a experiência fenomênica de ver uma imagem surge da ativação de um padrão na correspondente tela [display] no cérebro, na superfície do córtex visual. Kosslyn et al. (2006) exploram semelhente display no córtex visual, área V1, que tem natureza retinotópica , como mostrada na Fig. 3. O objetivo de Kosslyn ao propor esse display é encontrar um lugar no qual as imagens mentais experienciadas pelo sujeito pudessem ser afiguradas, tal como se daria num panorama e no qual o escaneamento mental (e outros processos ligados à imagética) teria lugar.

A respeito da afirmação da organização retinotópica, Pylyshyn chama atenção para estudos que mostram que há movimentos espontâneos dos olhos durante as imagens mentais (Brandt \& Stark, 1997):

Se padrões fossem projetados no córtex visual durante a imagética mental, e houvesse movimentos dos olhos, a interpretação dos padrões seria embaralhada [...]. Além disso, a imagem mental está fixa em espaço alocêntrico - a sua inclinação natural permanece fixa no espaço extrapessoal, quando alguém vira a cabeça ou o corpo e mesmo quando se anda em torno dele (Pylyshyn, 2007, p. 139).

Além disso, o autor critica o modelo de Kosslyn chamando atenção para o fato de que o display no córtex visual primário é bidimensional (2-D), ao passo que as imagens mentais podem ser 3-D. Contesta, assim, a afirmação de que um display afigura profundidade da maneira como realizamos ao desenhar em um plano), pois perde-se a ideia essencial de que "a imagem pictórica deve ser a interpretação tal como experienciada, e não uma figura a partir da qual tal interpretação é derivada" (Pylyshyn, 2007, pp. 140-1). Kosslyn (1981, p. 63) afirma, a esse respeito, que não somos capazes 
de imaginar objetos 4-D devido à incapacidade da representação imagética de dar conta da representação de formas em quatro dimensões.

Segundo Pylyshyn (2007, p. 120):

A experiência consciente que nós temos quando imaginamos alguma coisa (tal como quando temos uma "imagem mental") é muito parecida como aquela de ver alguma coisa. É esse aspecto da experiência que a torna problemática como fonte de evidência sobre a natureza de nossa representação mental. Isso porque a experiência que temos é a de ver um mundo percebido e não a dos nossos estados mentais.

Pylyshyn salienta que a percepção de informação de um display mental teria que ser muito diferente da percepção visual de uma tela externa a nós. Afinal, as imagens mentais não apresentam propriedades básicas da visão, tais como ambiguidade, biestabilidade, ilusões visuais e movimento aparente. Além disso, imagens não são objetos intencionais: elas são “interpretações conceituais” (Pylyshyn, 2007, p. 141).

Pylyshyn aponta um problema que considera ainda mais sério a respeito do uso de conteúdos das experiências imagéticas conscientes para inferir algo sobre os processos ou estruturas que estejam por trás. Trata-se da dificuldade do modelo pictorialista para explicar as evidências de "visão sem consciência" (vision without awareness), tais como cegueira a mudança, em que o sujeito não percebe alterações entre duas fotos de uma mesma cena (Pylyshyn, 2007, pp. 106, 144). A cena é diferente, mas ela é interpretada como sendo a mesma; tal situação não poderia se dar com uma imagem mental, pois esta já é interpretada. Para Pylyshyn (2007, p.145), o conteúdo da experiência consciente é o resultado de uma complexa rede de influências, até mesmo de processos inconscientes, o que aponta para muitos tipos e níveis de representação e não para uma correspondência simples entre uma experiência imagética e um nível representacional. 


\subsection{Conhecimento tácito versus arquitetura cognitiva}

Por que existe um problema sobre imagens mentais? Pylyshyn (2002), em seu artigo "Mental imagery: in search of a theory", responde que há uma "tendência para a experiência subjetiva" (pull of subjective experience), que faz com que quando vemos o mundo, imaginamos que ao fecharmos os olhos algo que é semelhante a essa cena está por trás daquilo que observamos, ou seja, a forma das estruturas mentais seria muito mais semelhante a uma figura do que a uma descrição linguistica.

Além disso, em situações como a de um jogador de beisbol que pega uma bola, os pensamentos com imagens se dão de maneira tão dinâmica, segundo esse autor, a nos fazer crer que a nossa "arquitetura imagética inerentemente e automaticamente obedece às leis relevantes de natureza" (Pylyshyn, 2002, p. 159). Isso parece ocorrer porque conseguimos predizer o comportamento de corpos em movimento no espaço que não seríamos capazes de calcular analiticamente. Isso nos leva a crer que são as próprias imagens mentais que têm, em si, "propriedades privilegiadas", como descreve o modelo pictorialista (Kosslyn et al., 2006) e não que o sujeito tenha controle sobre a sua imagem, seus conteúdos imagéticos.

Porém:

Ninguém nega que o conteúdo do comportamento de nossas imagens mentais pode ser o resultado daquilo que pretendemos que nossas imagens mostrem, do que sabemos sobre como as coisas no mundo aparecem e funcionam, e da maneira como a nossa mente ou o nosso sistema imagético nos constrange. A questão importante sobre as imagens mentais é: quais propriedades e mecanismos são intrínsecos ou constitutivos de ter e utilizar imagens mentais, e quais surgem por causa daquilo que acreditamos, intencionamos ou atribuímos à situação que estamos imaginando (Pylyshyn, 2002, pp. 159). 
Trata-se aqui de uma distinção fundamental nas ciências cognitivas desenvolvida entre outros por Pylyshyn (1981) e Fodor (1968), e constantemente utilizada por Pylyshyn em suas críticas ao modelo pictorialista -, a distinção entre propriedades relativas à arquitetura cognitiva e propriedades que dizem respeito a crenças do sujeito a respeito de como as coisas seriam em dada situação - o conceito de "conhecimento tácito".

A arquitetura cognitiva "refere-se ao conjunto de propriedades da mente que são fixas com respeito a certos tipos de influência. Em particular, a arquitetura cognitiva não é diretamente alterada por mudanças em conhecimento, objetivos, utilidades ou quaisquer outras representações (por exemplo: medos, esperanças, fantasias etc.)” (Pylyshyn, 2002, p. 160).

Já o conhecimento tácito está envolvido no conhecimento que os sujeitos têm de como o mundo é, e de como devemos agir. Por exemplo, "sabemos" que os líquidos e sólidos, quando misturados a temperatura ambiente, se comportam de certa maneira. Se misturarmos uma jarra de água a um recipiente cheio de areia, intuiremos que a água transbordará. Conseguimos predizer o comportamento de corpos cujas equações físicas sequer sonharíamos tratar matematicamente, tais como a de uma moeda girando até parar.

Segundo Pylyshyn (2007, p.128):

Se o fenômeno se dá porque a pessoa acredita que é assim que as coisas se desdobrariam no mundo (devido a uma teoria do senso comum ou devido a uma rememoração de algo semelhante que se deu no passado), então o fenômeno revela não uma propriedade do mente-cérebro, mas somente uma propriedade das crenças ou conhecimento (frequentemente tácito) da pessoa sobre como as coisas funcionam no mundo.

Por um lado, Pylyshyn procura reinterpretar os resultados obtidos pelos experimentos de Kosslyn a partir da noção de conhecimento tácito, e por outro, mostrar 
através de experimentos que as vivências imagéticas não dependem de uma arquitetura imagética (mesmo que isso existisse). Assim, é bem possível que uma pessoa imagine uma bola de chumbo caindo muito mais rapidamente do que uma bola de isopor: essa imagem surge não por causa da maneira como a mente ou o cérebro é constituído, mas devido a um conhecimento tácito que, neste caso, pode ser equivocado.

Pylyshyn reinterpreta através da noção de conhecimento tácito outra evidência importante para o programa de pesquisa de Kosslyn: a variável tempo como medida nos experimentos de escaneamento e rotação imagética. A razão pela qual um evento leva mais tempo para ocorrer, no experimento de escaneamento mental de imagens, não se deve à maneira como a arquitetura mental é constituída, mas sim aos conhecimentos tácitos a respeito desse assunto.

Ainda sobre as diferenças entre propriedades da arquitetura e propriedades relacionadas ao conhecimento tácito, Pylyshyn (2007, p. 129) aponta que o uso do tempo de reação em experimentos psicológicos tornou-se um bom indicador da complexidade computacional do processo estudado (indicando o número de operações mentais realizadas), mas que ele pouco diz sobre a arquitetura cognitiva subjacente, salvo que ela é capaz de armazenar crenças (conhecimento tácito) e fazer inferências a partir dessas crenças, inferências essas que duram o intervalo de tempo indicado pelo tempo de reação.

A partir da quarta fase do debate, que se iniciou em 2002, Pylyshyn desenvolveu argumentos adicionais aos baseados no conhecimento tácito. Nessa última fase, Pylyshyn reavaliou o debate sobre a imagética à luz de três décadas de experimentos e simulações computacionais em seu laboratório, e face aos avanços por parte da neurociência a respeito da compreensão das estruturas e áreas envolvidas nos processos conscientes. Reconhecendo o interesse intrínseco dos novos experimentos envolvendo 
neuroimagem, argumentou que os mesmos não suportam a existência de nenhum tipo de display afigurador nas imagens mentais.

Um dos pontos centrais da reavaliação de Pylyshyn (2007) nessa fase está na questão da representação de espaço na mente, que o modelo de Kosslyn toma como cerne da questão sobre imagética. Pylyshyn sugere, nesse momento de suas pesquisas, para além da opção do conhecimento tácito a que vinha apelando para explicar as hipóteses do modelo pictorialista, uma abordagem que permite que se fale numa "representação" espacial sem que seja necessário falar em internalização de propriedades espaciais, eliminando portanto o "espaço interno" do modelo pictorialista (Pylyshyn, 2007, p.124).

\subsection{O problema da conexão entre percepção e mundo}

Para além do problema da forma das representações por trás das imagens mentais, em seu trabalho Things and places: how the mind connects with the world (Coisas e lugares: como a mente se conecta ao mundo), Pylyshyn (2007) levanta uma série de questões relacionadas à ligação das representações mentais ao mundo:

Descobri que, vindo de uma perspectiva muito diferente, eu tomara uma posição sobre um conjunto de questões sobre as quais os filósofos vinham se preocupando pelo menos pelos últimos cinquenta anos: questões sobre como os conceitos se conectam ao mundo, sobre se há representações não-conceituais e, se houver, como elas são, sobre a fundamentação dos estados mentais em conexões causais com estados do mundo e, mais recentemente, sobre como as representações mentais - tais como aquelas por detrás das imagens mentais - adquirem o seu caráter aparentemente espacial, que as permite serem utilizadas no pensamento da maneira como os diagramas são utilizados (Pylyshyn, 2007, p. 1).

As respostas tradicionais para esse problema, de como as representações se relacionam com o mundo que representam, evocam, por um lado, uma relação 
semântica (referencial), que se estabelece quando o que a proposição exprime é de fato o estado de coisas que ocorre, e por outro, uma relação causal, entre propriedades dos objetos e experiências subjetivas (Pylyshyn, 2007, p. 5). Uma das preocupações perenes na filosofia da mente tem sido reconciliar essas duas relações, ou seja, como o intensional pode ser reconciliado com o causal.

O problema permanece em aberto, apesar das tentativas louváveis mas incompletas de Kripke (buscando os referentes de nomes próprios no ato do batismo desses nomes) e Dretske (em sua abordagem informacional). A relação causal tem sido trabalhada por teorias científicas e pela ciência cognitiva. A relação semântica envolve a correspondência entre representações mentais e referentes no mundo externo, ou em mundos possíveis. Mas não há uma maneira transparente em que o mundo possa causar o conteúdo particular de uma representação: basta pensar em um desenho do cubo de Neckar, que leva a diferentes representações, conforme vemos uma face ou outra saltar para frente (Pylyshyn, 2007, p. 5).

No entanto, em geral, para o cientista da visão, esse problema não se coloca, e ele supõe que a teoria causal possa dar conta de tudo, ao tomarem a representação e o conteúdo representacional como dados. É esta limitação que está por trás da concepção equivocada dos pictorialistas. 


\section{Capítulo 4}

\section{Outras Críticas à Teoria da Afiguração}

\subsection{A crítica de Noë à concepção fotográfica da teoria visual}

Outros autores questionam a necessidade da postulação de uma representação de natureza pictórica na mente para dar conta das nossas experiências imagéticas. Dentre eles está Alva Noë (2004).

O debate sobre a imagética parte de uma certa concepção sobre a fenomenologia da experiência perceptual, segundo a qual, quando abrimos os olhos, vivenciamos uma “detalhada e rica experiência afiguradora [picture-like] do mundo, uma que o representa o mundo em foco nítido, detalhes uniformes e alta resolução do centro até a periferia. Chamemos essa concepção de concepção fotográfica [snapshot conception] da experiência” (Noë, 2001, p. 2). Essa concepção fotográfica da teoria visual está na base de boa parte das teorias sobre a visão. Segundo essa concepção, acredita-se que o sistema visual integra uma imagem interna a partir das informações fragmentadas que recebemos na forma de entradas [inputs] da retina.

Segundo o autor, a solução “ortodoxa” de integrar um panorama é um equívoco, pois confunde a pergunta enganadora, "por que vemos tanto com base em tão pouco?", com a real pergunta que uma teoria da visão deveria fazer: "por que nos parece que vemos tanto quando de fato vemos tão pouco?”

Essa mudança de perspectiva enfoca nossa atenção ao fato de que nossa experiência do visível estende-se para além do que é realmente visto (caso da percepção de detalhe), trazendo dificuldades para a postulação de um panorama interno, no qual 
haveria um mapeamento estrutural de partes da representação a partes do objeto representado. Segundo este autor:

[...] todo esse negócio de projeção e perspectiva é uma pista falsa [red herring]. Todo mundo concede que nós não vemos imagens nos olhos. Mas é normalmente tacitamente suposto que, mesmo assim, as imagens nos olhos, reproduzidas através do sistema visual incorporado no cérebro, são, em algum sentido fundamental, essenciais à visão. Ver, acredita-se, está de alguma forma ligado à imagética! (Noë, 2008, p. 662)

Para Noë, o mundo se mostra a nós não de maneira a ser representado numa figura, mas enquanto nos está disponível. Uma experiência visual seria assim um encontro com uma cena, um episódio de acesso a ela. Nós não vemos o que é projetado de um ponto, mas “o que está disponível de um determinado lugar”.

Pylyshyn caracteriza a concepção fotográfica da experiência de maneira semelhante a Noë. Segundo Pylyshyn, pressupõe-se que quando vemos o mundo, recriamos um panorama daquilo que é visto em nossas mentes, numa representação pictórica bidimensional sobre a qual operamos de diversas maneiras (extraindo informações da representação, manipulando, rodando, etc.).

\subsection{Discussão sobre o tamanho e resolução da imagem mental}

Como vimos na seção 2.1, Kosslyn desenvolveu um modelo a respeito do processamento envolvendo imagens na mente, de tal forma que é possível falar numa "arquitetura imagética". Esse termo se aproxima da noção de "arquitetura cognitiva" de Pylyshyn, na medida em que ambos os modelos inspiram-se em explicações advindas da inteligência artificial, que tomam conteúdos na mente como símbolos, e processos como operações sobre símbolos. Ou seja, a arquitetura imagética envolve ideias, como a 
transformação de imagens periféricas por um "processador" e a geração de imagens a partir de representações profundas, que nada mais são do que abstrações advindas da inteligência artificial, por analogia a como os computadores funcionam.

No entanto, por ser um psicólogo próximo das ciências biológicas, o programa de pesquisa elaborado por Kosslyn mescla conceitos advindos dessas disciplinas, de tal forma que essa "arquitetura imagética" é definida primariamente no cérebro (e não a partir da mente, como na visão pylyshynista) e depende das teorias da biologia sobre processamento da informação visual.

Uma das características dessa arquitetura imagética kosslynista, que foi geradora de grandes discussões, é que ela prevê que a imagem bidimensional registrada no cérebro tenha um tamanho e mesmo um grau de definição ou resolução. Seria como imaginar um elefante e ao lado dele um pequeno coelho. Supostamente, nessa imagem mental, é possível realizar uma aproximação do olho da mente em relação àquela imagem, tornando o coelho mais próximo.

Em primeiro lugar, o meio tal como "visto" pelo olho da mente deve ter uma resolução limitada. Se objetos são imageados muito pequenos, partes devem ser mais difíceis de se ver. Isso é verdade na percepção visual; e se o mesmo meio é usado na imagética e na percepção, deve ser verdade na imagética também. Em segundo lugar, o meio tem uma extensão espacial limitada: as imagens não podem ser indefinidamente grandes, mas devem ser limitadas pelo tamanho do meio e pelo escopo do olho da mente. (Kosslyn, 1983, p. 55)

Para Kosslyn, faz-se necessária a postulação do tamanho e do tempo de varreudura da imagem mental porque é a melhor hipótese para explicar a relação linear entre tempo de reação e distância entre as partes da imagem. No entanto, as teses acerca do tamanho e resolução da imagem mental geraram muita crítica e debate, e talvez seja a parte da teoria mais difícil de aceitar (ver, por exemplo, Tye, 1991).

Recordemos um dos experimentos: para duas imagens de um coelho, um grande (ao lado de uma mosca) e outro pequeno (ao lado de um elefante), pergunta-se ao 
sujeito se o coelho tem orelhas, e o resultado foi de que demorava mais tempo para encontrar os detalhes na imagem menor do que na maior. Os sujeitos chegavam a relatar que pareciam precisar "dar um zoom" na imagem para ver melhor.

A questão de Pylyshyn (2007, p. 131) a respeito desse experimento é se, mais uma vez, isso não se dava devido ao que os sujeitos sabiam tacitamente a respeito de como é ver um coelho pequeno, ou seja, com pouca definição?

Pylyshyn também argumenta que há evidência neurocientífica de que uma imagem fenomênica maior não é de fato maior no córtex, de forma que "uma explicação baseada na limitada resolução cortical é irrelevante” (Pylyshyn, 2007, p. 132). Argumenta ainda que a resolução cortical se aplica somente à resolução da informação que se origina na retina, e não a informações que se originam internamente, da memória, e que são projetadas na superfície do córtex.

A crítica geral de Pylyshyn à interpretação dada por Kosslyn para esses experimentos é que a teoria da afiguração incorre em uma "falácia intencional", ao atribuir conteúdos da experiência imagética a uma estrutura subjacente ou ao substrato cerebral, como se esse tivesse necessariamente a mesma forma da experiência imagética.

\subsection{A crítica de Dennett ao teatro cartesiano}

Apesar de seu valor na ciência da psicologia, a introspecção é um método que sempre esteve sujeito a críticas. Dennett (1969) já apontava que postular uma representação de natureza pictórica por trás da experiência imagética, com limitação espacial e de resolução, é resultado da "armadilha da introspecção", que nos faz 
confundir os níveis pessoal e subpessoal, em nos fazer crer que podemos "olhar para dentro" e observar com um "olho interno" as funções ou mecanismos de nossas mentes.

A armadilha pode ser reiterada da seguinte maneira:

se imaginar é ver alguma coisa, então deve haver alguma coisa que se está vendo - deve haver algo na cabeça que desempenha um papel análogo àquele desempenhado por uma cena que se está realmente percebendo (e é claro, deve haver algo desempenhando o papel do olho, apesar de isso ser menos mencionado) (Pylyshyn, 2007, p. 125).

Pylyshyn também alerta para os perigos da introspecção:

É precisamente o poder da introspecção, por um lado, fornecer uma janela para sobre o que estamos pensando, mas por outro lado, nos enganar em fazer crer que podemos ver a forma na qual os nossos pensamentos estão codificados e a natureza do processo de pensamento em si, que cria dificuldade em chegar a um entendimento da natureza da percepção e do pensamento (Pylyshyn, 2003, p. 286).

Para Dennett, o modelo da afiguração é fruto de um resquício de dualismo na teorias da mente que o sustenta. Segundo esse autor, através da introspecção ficamos convencidos de que, ao "olhar para dentro", "a consciência está repleta de uma variedade de objetos e qualidades peculiares que da qual não se pode dar conta por uma teoria puramente física da mente" (Dennett, 1969, p. 128).

Defende que os autores que postulam uma representação por imagens estão presos a um modelo de consciência cuja falha intrínseca está na necessidade de haver um tempo e lugar no qual um discriminador unificado inspeciona ou processa as imagens, o lugar por onde os estímulos passariam para se tornarem conscientes.

Há uma grande semelhança do modelo da afiguração com o modelo esboçado por René Descartes, com a diferença de que no dualismo cartesiano o "lugar central" pelo qual os estímulos deveriam passar era ocupado pela glândula pineal. Ao defender que há imagens mentais, o problema que surge é: imagens dentro do cérebro para quem? Uma imagem requer um observador, mas existem observadores dentro do 
cérebro? E o que fazer dos observadores que será preciso postular dentro do cérebro dos observadores? A postulação de um homúnculo nos leva a um regresso infinito de observadores. Dennett (1991, p. 137) denomina "Teatro Cartesiano" às teorias que abandonaram o dualismo mas retêm esse lugar central para projeção de estímulos.

O modelo do Teatro Cartesiano concebe que há um lugar no cérebro onde tudo se junta e é registrado para a análise subjetiva. Um caminho para se destrinchar a natureza da consciência e criticar a concepção do Teatro Cartesiano é fazer uma análise do tempo subjetivo, como feito em artigo escrito por Dennett \& Kinsbourne (1992), pois o modelo do Teatro Cartesiano implica que propriedades temporais dos eventos mentais que carregam conteúdo e que se localizariam neste meio representacional privilegiado determinariam a ordem temporal subjetiva.

Para Dennett, parte do problema está em que extrapolamos um modelo de consciência a partir de intuições da psicologia do senso comum. Em nosso cotidiano macroscópico, eventos podem ser ordenados satisfatoriamente em categorias como “ainda não observado" ou "já observado". Mas quando tentamos estender esse método para fenômenos envolvendo períodos muito curtos de tempo, determinando a "ordem de chegada" de trens de impulsos no cérebro, como determinar qual o ponto de chegada desses impulsos? O cérebro é gigante na escala celular, e a ordem de chegada é incompletamente definida até que especifiquemos um destino específico, conforme salientado por Minsky (1985, p. 61). Em suma, não há como estabelecer uma sequência unívoca de eventos, ou de simultaneidade, no nível subjetivo do observador.

Para Dennett (1991, p. 108), “a ideia de um centro especial no cérebro é a má ideia mais tenaz atrapalhando nossas tentativas de pensar sobre a consciência". Ela aparece em diversas teorias da mente, reafirma-se na tese da "unidade da consciência", e também na noção de que há o externo e o interno, como se houvesse "um ponto tal 
que toda manipulação feita de um lado dele seria pré-experencial, e toda manipulação feita do outro seria pós-experencial".

A teoria da formação do panorama interno, ou de que há um local definido onde se forma uma representação, confronta-se assim com essas dificuldades a respeito do tempo subjetivo no cérebro e da causalidade dos estados mentais. Além disso, nem todos os estados em eventos cerebrais deixam traços conscientes, muitos deles simplesmente desaparecem após alguns instantes. Não faz sentido falar num lugar pelo qual os trens causais devem passar para "depositar conteúdos conscientes", já que os processos que agem combinando e comparando conteúdos, e realizando a pretendida unificação [bind], estão espalhados e não agrupados num ponto de decisão. Assim, o “ponto de vista do observador” é espalhado (Dennett \& Kinsbourne, 1992, p. 184).

Segundo os autores, caso o cérebro pudesse realizar computações com velocidade próxima à da luz (que é a tendência dos computadores no futuro), esse falta de definição espaço-temporal no cérebro não seria significativa. Mas, dada a distribuição espacial dos processos cerebrais, há uma indeterminação fundamental nos processos conscientes que gira em torno de $1 / 20$ de segundo (50 ms).

No entanto, temos uma noção subjetiva de ordenamento temporal: como é que ela surge? Para responder a esta pergunta, os autores propõem o chamado Modelo dos Múltiplos Esboços (multiple draft model), segundo o qual as discriminações de conteúdos são realizadas apenas uma vez (num dado lugar no cérebro) e entram em contato com outros processos numa espécie de reelaboração, reedição constante (no tempo e espaço), tal como uma narrativa:

Todas as operações perceptuais, e de fato todas as operações do pensamento e da ação, são completadas por processos multi-tarefas de interpretação e elaboração, que ocorrem em centenas de milissegundos, período no qual várias adições, incorporações, remendos e revisões de conteúdo podem ocorrer, em várias ordens. Detectores ou discriminadores de características só precisam ocorrer uma vez. Ou seja, quando uma "observação" localizada, especializada, for feita, o 
conteúdo de informação fixado desta maneira não precisa ser enviado para outro lugar para ser rediscriminado por algum discriminador mestre. Em outras palavras, ele não leva a uma reapresentação de características já discriminadas, para o benefício da plateia do Teatro Cartesiano (Dennett \& Kinsbourne, 1992, p. 185).

Com o Modelo dos Múltiplos Esboços, Dennett \& Kinsbourne pretendem eliminar o problema fundamental do homúnculo, implícito no modelo cartesiano. Afinal, uma representação no cérebro para quem? Representações parecem exigir um observador, mas observadores dentro da mente não parecem fazer sentido. Para além disso, uma vez que postulamos uma representação, temos o primeiro passo num regresso infinito de observadores na mente.

Outro problema do modelo cartesiano, que o modelo dos múltiplos esboços procura evitar, diz respeito à existência de um fluxo único de consciência, noção presente em inúmeras teorias sobre a consciência. Dado que no modelo há múltiplas narrativas, não haveria uma única "narrativa canônica" privilegiada, que seria o equivalente à noção de fluxo de consciência. Ao invés disso, dá-se a ocorrência de conteúdos até mesmo conflitantes, e continuamente revisados e reeditados. Resta aguardarmos para saber qual o respaldo desse modelo na neurociência.

Dennett \& Kinsbourne invocam o apoio de alguns experimentos, como o do "fenômeno $\varphi$ " (fi), descoberto por Wertheimer, em 1912. Ele observou que duas luzes piscando alternadamente em uma linha de trem geravam, a uma certa distância (cobrindo um ângulo de $4^{\circ}$ ), a ilusão de movimento (para cima e para baixo) entre as duas luzes. Quando as duas luzes têm cores diferentes, Kolers \& von Grünau (1976) descobriram que se cria a ilusão de mudança de cor, à meio caminho entre as duas luzes. Esse resultado surpreendente levanta a dúvida de como a consciência pode prever qual vai ser a nova cor do objeto virtual antes mesmo de a luz correspondente acender. 
A explicação clássica para este fenômeno (no caso de luzes de mesma cor) foi dada já em 1931 por van der Waals \& Roelofs, que "propuseram que o movimento interveniente é produzido retrospectivamente, sendo construído depois do segundo flash de luz, e "projetado para trás no tempo"” (Dennett \& Kinsbourne, 1992, p. 186).

Os autores então examinam mais três experimentos, incluindo os dois famosos experimentos de Benjamin Libet (2004). O primeiro deles explicita melhor o que seria a “projeção para trás no tempo", mencionado acima. Não precisamos entrar nos detelhes deste experimento bem conhecido, bastando mencionar que quando um tenista rebate uma bola rápida, ele só toma consciência do que fez $1 \frac{1}{2}$ segundo depois da rebatida, mas aí, espontaneamente, ele "pré-data" o instante associado à sua memória da rebatida em $1 / 2$ segundo, para que ela se encaixe na sequência temporal correta em que sua ação de rebater foi tomada.

Dennett \& Kinsbourne primeiro descartam qualquer explicação dualista para o fenômeno (como esboçada por Eccles e pelo próprio Libet), e qualquer ideia de que um evento futuro possa influir o passado. O seu ponto é argumentar que, no modelo clássico do Teatro Cartesiano, faz sentido distinguir dois cenários distintos (que definiremos a seguir), ao passo que no modelo dos Múltiplos Esboços, esses dois cenários são indistinguíveis, e portanto não faz sentido separá-los (Dennett \& Kinsbourne, 1992, p. 190).

Esses cenários são chamados "orwelliano" e "stalinesco", e ambos envolvem a criação de uma falsa memória, por exemplo a memória de que uma maratonista estava usando óculos no domingo, durante uma corrida que o sujeito estava assistindo (sendo que na verdade ela não estava usando óculos). No cenário orwelliano, a falsa memória foi inserida na segunda-feira; no stalinesco, a falsa memória surgiu no domingo mesmo, durante a corrida, como uma alucinação. Está claro que, subjetivamente, ambas as 
situações são indistinguíveis, na terça-feira. A abordagem do Teatro Cartesiano, porém, crê que ambas as situações são distintas, mesmo no experimento $\varphi$, pois em princípio é possível determinar precisamente os pontos espaço-temporais em que ocorrem os eventos em questão: assim, faz sentido falar em "projeção para trás no tempo". Porém, para a abordagem dos Múltiplos Rascunhos, esta afirmação não faz sentido, pois os eventos em questão estão muito próximos entre si.

\title{
4.4 O problema dos qualia e a cegueira a mudança
}

Vimos, na seção 4.1, que para Noë, o problema que uma teoria sobre a visão tem que enfrentar está em explicar o fato de que o nosso

\begin{abstract}
contato direto com o mundo na forma de informação na retina é tão limitado: [...] há duas imagens da retina e não uma, elas são distorcidas, pequenas e viradas ao contrário. [...] Além disso, o poder de resolução dos olhos é limitado e não uniforme; fora da região de alta resolução da fóvea, a retina é praticamente cega para cores e os seus poderes de discriminação são severamente limitados (Noë, 2001, p. 2).
\end{abstract}

Esse problema é resolvido tradicionalmente supondo-se que o que acontece é que o cérebro integra essa informação numa representação interna estável e detalhada, criando o panorama do mundo a que se refere Pylyshyn (2003), e que examinamos na seção 3.1.

Essa representação, segundo a psicologia do senso comum, tem ainda algumas características, a saber, são acessíveis somente ao sujeito da representação (acesso de primeira pessoa), são intencionais (envolvem a experiência consciente) e são inefáveis (não há como se traduzir esses aspectos fenomenológicos em palavras). 
A partir dessa caracterização da experiência subjetiva foi cunhado o conceito de qualia (singular: quale), termo em latim para qualidade, e que supostamente se refere a tais experiências, que somente o sujeito das mesmas pode acessar, como a qualidade subjetiva do calor, de uma dor, "como é para mim" essa cor ou como foi para mim escutar uma velha canção no rádio.

Qualia, ou qualidades fenomênicas, podem ser caracterizadas, segundo Loar (1997, p. 597), como as características da experiência subjetiva ou qualidades da experiência subjetiva que encontramos quando "olhamos para dentro" através do exercício da introspecção.

Seja na forma de dores, imagens, a vermelhidão do vermelho, cheiros, gostos ou sons, os qualia são vagamente definidos como qualidades subjetivas, como a experiência tal como é apenas para mim, sujeito dessa experiência (com certa constituição biológica e social), num dado instante $t$. Trata-se, portanto, de uma propriedade relacional (relacionada a mim, num dado instante $t$ ).

Os qualia são aspectos fenomênicos - relativos à consciência - de nossa vida mental, somente acessíveis através da introspecção. Ou seja, não consistem dos estímulos (visuais, auditivos, gustativos etc.) recebidos pelo meu aparato sensório, mas de reações que resultam desses estímulos.

Os próprios filósofos não chegam a um consenso a respeito de uma definição do termo, e neurocientistas passaram a adotá-lo para designar tudo aquilo que não seja “processamento periférico" e sim relacionado à consciência. Dennett (1991, p. 56) usa o termo "fenomenologia", caracterizando tudo o que seja conteúdo presente na consciência, tal como sensações, dores, imagens, sons etc., mas diferenciando-os dos processos de pensamento e compreensão (apesar de um poder acompanhar o outro). Os 
qualia seriam "as qualidades intrínsecas" de nossa fenomenologia (Dennett, 1991, p. $65)$.

A definição desse conceito passa, no entanto, por uma série de dificuldades conceituais levantadas pelos críticos da concepção imagética, como Dennett, Tye, Pylyshyn e Noë, entre outros. Kosslyn e Pylyshyn não se pronunciam sobre os qualia. Para Kosslyn, consciência é matéria de processamento periférico. Pylyshyn trata da questão a partir da perspectiva do conhecimento tácito.

Segundo Dennett, é mais fácil dar exemplos de qualia (qualia para cor: a vermelhidão do vermelho, o vermelho vivo que eu vejo quando observo um tomate maduro, por exemplo) do que definir essa noção. A própria definição de qualia seria suspeita, já que as torna inacessíveis a medições objetivas e a explicações por parte de uma ciência de terceira pessoa. Seria uma formulação genérica que não passa de "uma conspiração de pressuposições não examinadas e de elaborações definidas de maneira circular" (Dennett, 2005, p. 79).

“Os qualia de cores não são as características objetivas da luz, as características capturadas em filme ou vídeo colorido; eles são supostamente os efeitos puramente subjetivos em você de ver o limão, ou a fotografia do limão, ou o vídeo do limão" (Dennett, 2005, p. 80). Mas são os qualia os próprios aspectos fenomênicos da experiência, ou são um efeito, uma resposta, ou uma disposição a um aspecto fenomênico?

Quando realizamos a redução necessária a uma ciência da mente, mas ainda ficamos com um "resto experiencial", uma "riqueza extra" a que não se pode fazer referência de forma científica numa possível teoria sobre a mente, estamos afirmando sobre os "qualia" que são entidades inescrutáveis dentro do método e domínio científico. Segundo Dennett (1991, p. 71), essa visão é muito comum entre 
neurocientistas. "Trata-se, na verdade, de dualismo; esses pesquisadores aparentemente concordam com Descartes que a mente não é o cérebro, e estão preparados para se resignar em ter uma teoria somente sobre o cérebro." Enfim, para Dennett o termo "qualia" não corresponde a nada, tratando-se de um entrave para uma ciência da consciência. Uma teoria da subjetividade, quando existir, deverá estar no domínio de uma ciência de terceira pessoa.

Para Dennett, a sedução da introspecção acaba servindo como autoridade sobre o que sabemos de nossas consciências. A concepção de subjetividade baseada em qualia confunde a experiência da visão com uma visão interna (ou a recriação de uma visão interna). Esta confusão surge de teses da psicologia do senso comum, como aquela que supõe que, ao experienciarmos imagens mentais, estamos observando a própria forma de uma representação pictórica na mente. Tal tese não é atribuída somente aos sujeitos, mas também faz parte das teorias pictorialistas da representação mental, cujo modelo mais bem acabado é o modelo formulado por Kosslyn, que defende a existência de representações imagéticas, quase-pictóricas na mente.

Com o objetivo de nos mostrar como o conceito de qualia é equivocado, Dennett explora diversos experimentos mentais, como o quining qualia, e também experimentos reais, como o da cegueira a mudança (change blindness), previsto por Dennett (1991, pp. 467-8) e descoberto na psicologia cognitiva por Rensink, O’Regan \& Clark (1997) (ver também O’Reagan \& Noë, 2001).

O experimento da cegueira a mudança consiste em mostrar ao sujeito, em flashes de $250 \mathrm{~ms}$, duas figuras praticamente idênticas (Fig. 5), com uma pequena diferença entre si (flicker), até que o sujeito perceba a mudança e pressione um botão. No exemplo apresentado pelos autores, trata-se da fotografia de uma cozinha, sendo que em uma das imagens, uma das portas da cozinha está pintada de outra cor. Sujeitos 
demoram em média 20 a 30 segundos para notar a diferença, o que é um lapso de tempo razoável se pensarmos que as imagens são mostradas uma série de vezes antes que se consiga perceber a diferença.

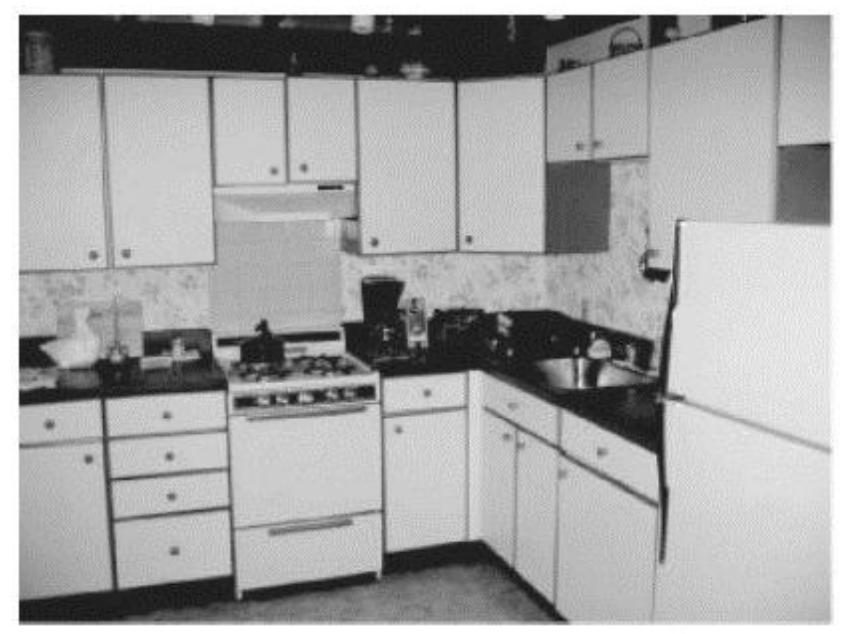
Figura 5:
Imagens usadas no experimento da cegueira a mudança. Com as fotos colocadas lado a lado, é fácil ver a diferença, mas quando elas aparecem indivi- dualmente, e são troca- das com um pequeno intervalo entre elas (flicker), a diferença fica mais difícil de notar (Dennett, 2005, p. 84).

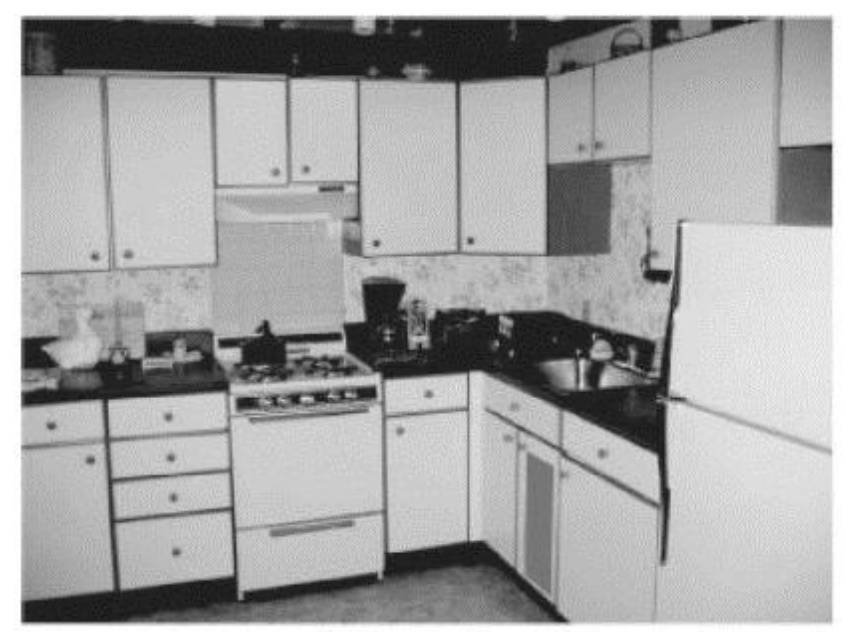

Repetindo o teste para sua audiência, Dennett (2005, p. 83) então pergunta aos espectadores uma questão com o objetivo de mostrar as confusões conceituais que cercam os sujeitos a respeito da noção de qualia: "antes que você pudesse notar a diferença, os seus qualia estavam mudando?” Em outras palavras, devemos dizer que os qualia distintos não existiam, ou que existiam mas não foram percebidos?

O problema para o "qualiófilo" nesse ponto está em que, de acordo com a 
definição de qualia, esses são acessíveis somente ao sujeito da experiência. O que dizer agora, antes de notar que a porta da cozinha da direita era colorida, dos qualia que foram percebidos pelo sistema visual primário, mas de que não tomei conhecimento? Ou eu tomei conhecimento sem ter conhecimento disso subjetivamente? Como ficaria nesse caso a definição de qualia?

Segundo Dennett, esses experimentos nos levam à conclusão bizarra de que nem mesmo o sujeito da experiência tem autoridade sobre os próprios qualia, já que nesse caso o sujeito estaria na mesma posição que qualquer ciência de terceira pessoa (tendo apenas acesso indireto) sobre as próprias experiências.

Essa parece ser uma conclusão estranha e indesejada, já que o conceito de qualia é definido como aquilo sobre o que o sujeito tem autoridade máxima, ou talvez o único que pode dizer algo a esse respeito, por se tratar de uma experiência privada, de qualidades que lhe são mais íntimas.

Tye (2009, p. xii) chama de "linha conservadora", na interpretação dos experimentos de cegueira a mudança, a posição segundo a qual nós de fato "vemos" [see] as diferenças entre as figuras, mas não as "reparamos" [notice]. Ele critica esta solução ao desafio de Dennett, defendendo que nós não vemos as mudanças de qualia enquanto não as reparamos. Tye se afasta das conclusões mais fortes dos teóricos da cegueira a mudança, como Noë e O’Regan, ao propor que “ver as coisas é um pouco como desenhar figuras dessas coisas com os olhos" (Tye, 2009, p. xiii).

Tye coloca a problemática do materialismo como a questão de como tratar a consciência subjetiva, Há uma tendência, entre os filósofos materialistas, de adotar uma "estratégia do conceito fenomênico" (the phenomenal-concept strategy), "aceitando que seja concebível e portanto consistentemente pensável que o caráter subjetivo, sentido, de nossa experiência não seja um fenômeno material". Porém, mesmo aceitando esta 
possibilidade lógica, eles concluem que de fato a mente consciência nada mais é do que matéria organizada (Tye, 2009, p. xi).

A conclusão de Tye é de que esta estratégia do conceito fenomênico é errônea, e que simplesmente não há conceitos fenomênicos, o que o aproxima de Dennett.

\subsection{Crítica aos qualia através de experimentos mentais}

Qualquer discussão sobre os qualia acaba tendo que fazer referência ao famoso experimento mental proposto por Frank Jackson (1982), conhecido como "o quarto de Mary".

Mary é uma neurocientista da visão, que vive no futuro, e que passou toda sua vida confinada numa cela monocromática, na qual tem contato com o mundo exterior apenas através de um monitor de câmeras de TV em preto e branco. Mary tem acesso a todo o conhecimento científico sobre a visão de cores, a física das cores, o funcionamento do cérebro, etc.

Num dado momento de sua vida, Mary é liberada de seu confinamento à cela monocromática, saindo para o mundo em que vivemos. A pergunta que se faz é: Mary aprenderá alguma coisa nova sobre a visão? Ela terá uma experiência nova, uma descoberta? Ou já que ela possui todo o conhecimento científico sobre a visão em cores, não há nada a ser aprendido quando finalmente Mary vir um objeto colorido?

A resposta mais aceita entre os filósofos da mente tende a concordar com a colocação original de Jackson. Primeiro, de fato Mary vem a conhecer algo novo, qualia de cores, e portanto qualia existiriam. Em segundo lugar, o "argumento do conhecimento": como de fato ela veio a conhecer algo de novo, mesmo que por contato 
direto (by acquaintance), conclui-se que o fisicalismo é falso (ou seja, nem tudo no Universo é físico-químico-biológico), pois uma das premissas do argumento era que Mary teria todo o conhecimento físico a respeito da neurociência da visão de cores.

Para os que aceitam a conclusão de que os qualia existem, o aparentemente "difícil” problema dos qualia ou da consciência consiste na relutância em aceitar que a "riqueza" do mundo subjetivo possa ser reduzida às explicações da neurociência atual. Assim, essa "riqueza extra" deveria se traduzir num outro tipo de explicação, para além da ciência, ao menos a de que se dispõe atualmente. Segundo Dennett (2005, pp. 107-8), essa linha de argumentação é a perseguida por Jackson e Chalmers, entre outros, e ela insere um aspecto dualista na teoria, pois permite que se faça referência a algo que não é físico ou científico, ao se referir à consciência ou a fenômenos da subjetividade.

A posição pessoal de Dennett tem sido classificada como um "materialismo ralo" [thin materialism], em oposição ao materialismo espesso [thick materialism] (Graham \& Horgan, 2000). Os "materialistas espessos" concordam que Mary ficaria espantada ao sair de seu quarto e ter a sensação subjetiva de cores, e a partir dessa premissa buscam resolver o problema, dentro dos cânones materialistas. A posição "materialista rala" de Dennett, próxima da de Tye, busca negar que Mary ficaria surpresa ao sair do quarto.

O que impediria Mary, liberada de sua clausura, de inferir qual cor estava vendo? Dennett (2005, p. 105) propõe um experimento alternativo, em que a neurocientista, ao sair do quarto, fosse apresentada uma banana azul. Ao invés de ser ludibriada, ela percebe a brincadeira: "Aha! Vocês tentaram me enganar! Bananas são amarelas, e esta é azul!” Ora, como Mary conhece tudo sobre a neurociência da visão, ela foi capaz de identificar quais dos nervos ópticos foram excitados, e exatamente quais 
regiões do cérebro foram estimuladas, e dessa forma ela foi capaz de identificar qual a cor da banana (independente de reconhecer ou não o quale da azulidão).

O objetivo de Dennett com essa linha de raciocíno, mais uma vez, como é comum em seus escritos, não está em propor algo factível, mas mostrar as falhas das teorias vigentes. No caso do "argumento do conhecimento", para Dennett, a premissa problemática está em que Mary deteria todo o conhecimento, o que leva a extrapolações absurdas. Com isso, o autor reitera sua posição anterior (Dennett, 1991), continuando a defender que o "resto experiencial" é uma forma errada de compreender a subjetividade.

Passarei a examinar, assim, alguns experimentos mentais ou bombas de intuição [intuition pumps] propostos pelo autor, de um total de quinze apresentados no artigo “Quining Qualia", de 1998, com a finalidade de mostrar que o conceito de "qualia" é vago e confuso.

A segunda bomba de intuição apresentada é denominada "máquina testadora de vinho". Dennett nos pergunta se um produtor de vinho poderia substituir os seus refinados degustadores humanos por uma moderna máquina computadorizada? Supondo que isso seja factível, a provocação feita pelo autor está em nos fazer pensar se a máquina sentiria o gosto do vinho como nós sentimos. "Se você compartilha dessa intuição, você acredita que existem qualia no sentido que busco demolir" (Dennett, [1988] 1993, p. 384).

Para compreender o que há de tão especial nessas qualidades, Dennett apresenta a tradicional análise do conceito de qualia, em termos de quatro propriedades essenciais: eles seriam inefáveis, intrínsecos, privados e diretamente apreensíveis na consciência. O autor então critica essa e outras dwfinições mais brandas.

Outra bomba de intuição apresentada por Dennett, em sua tentativa de minar o conceito pré-teórico e intuitivo de qualia, foi formulada originalmente por John Locke 
em 1690: o experimento mental do espectro invertido. Como saber se a cor subjetiva que eu vejo é a mesma que você vê, quando observamos um objeto colorido. Pois se mesmo se tivermos os qualia de amarelidão e violeteza trocados, nós nunca saberemos, pois usamos a linguagem da mesma forma para descrever a calêndula e a flor violeta. Para Dennett ([1988] 1993, p. 387), tal especulação não pode ser nem confirmada, nem falseada. Explorando variações deste experimento mental, argumenta que é impossível verificar a hipotética troca de qualia até para uma mesma pessoa, que sofresse uma intervenção cirúrgica: ela não teria como saber se foram os seus nervos ópticos que foram trocados com a cirurgia ou se foi sua memória da experiência fenomênica de antes da cirurgia que foi alterada.

Dennett critica a saída "infalibilista" que os qualiófilos costumam oferecer para a impossibilidade de distinguir duas ou mais situações envolvendo alterações subjetivas de qualia: "mas depois que tudo foi dito e feito, há ainda alguma coisa que eu sei de maneira especial: eu sei como estão as coisas comigo agora" (Dennett, [1988] 1993, p. 391-2). Mas se, na prática, nada se segue deste suposto conhecimento, qual o sentido de afirmar que se tem tal conhecimento?

Dennett adota aqui a estratégia verificacionista comum a Wittgenstein, a quem costuma citar em vários trabalhos. No caso do espectro invertido, por exemplo, não tenho como saber se o meu vermelho subjetivo é igual ao seu, mas temos um acordo com relação aos nossos comportamentos linguísticos. Como a suposta diferença subjetiva não pode ser discernida, não faz sentido afirmá-la.

Os qualia não são nem mesmo 'algo sobre o qual nada pode ser dito'; 'qualia' é um termo dos filósofos que não gera nada além de confusão, e no final não se refere a nenhuma propriedade ou característica (Dennett ([1988] 1993, p. 387). 


\section{Conclusões}

Afinal, quem ganhou o debate da imagética mental? Qual o status atual do debate da imagética mental?

Vimos nesse trabalho que os dois lados do debate, representado pelo pictorialismo de Kosslyn e pela abordagem de uma linguagem simbólica da mente de Pylyshyn (aliada da postura crítica de Dennett), têm sido capazes de realizar experimentos corroborantes, de criticar o programa rival, e se defender dos ataques. Ao mesmo tempo, vimos que ambos os programas se alteraram ao longo do tempo, de forma que é um bom exemplo de um debate construtivo, realizado nas fronteiras da psicologia, neurociência e filosofia.

Um dos problemas conceituais envolvidos no programa pictorialista é a proposta de "internalização de espaço", associado à proposta de um mapeamento no display interno do cérebro/mente, ou seja, a noção de que o espaço do mundo externo é representado de maneira espacial no cérebro.

Devido aos problemas empíricos e conceituais da hipótese literal do display interno, relacionados com a suposição de que a imagem mental teria propriedades semelhantes às da visão primária, como ângulo visual, definição e tamanho, Kosslyn lançou mão de um conceito mais fraco de display, o conceito de "espaço funcional". Exploramos as críticas de Pylyshyn a essa noção, segundo as quais as propriedades espaciais estariam calcadas nas "propriedades privilegiadas da arquitetura", e sua defesa da importância do conhecimento tácito para a explicações dos experimentos de tempos de reação.

Kosslyn não mudou de posição com os achados em técnicas de imageamento do cérebro em áreas topograficamente organizadas. Mas segundo os críticos da posição pictorialista, esses dados não podem resolver os problemas conceituais 
inerentes à teoria da afiguração. Pois afinal, a pergunta colocada por Pylyshyn e Noë, levando em consideração os experimentos advindos da psicologia da percepção, tais como o da cegueira a mudança (change blindness), torna-se discutível a possibilidade de uma correspondência simples entre aparência fenomênica e um nível de representação.

Para Pylyshyn, as experiências imagéticas não podem revelar a arquitetura subjacente. $\mathrm{O}$ fato de levar mais tempo para escanear uma figura de um ponto a outro não se deve a uma restrição ou propriedade da arquitetura imagética, mas a propriedades daquilo que o sujeito acredita ou sabe tacitamente sobre como as coisas se dariam no mundo naquela situação.

Mesmo o apelo a um espaço funcional, forma branda do display interno, não salva o programa pictorialista da postulação desse nível de representação. Pylyshyn e Dennett, com seu Modelo dos Múltiplos Esboços, se alinham na proposta de que os conteúdos conscientes não constituam um nível distinto de representação, havendo uma mistura de níveis.

Em minha análise do debate, as considerações críticas de Pylyshyn e Dennett contra a tese pictorialista e contra o Teatro Cartesiano se mostraram mais convincentes. O fato de Kosslyn ter voltado atrás e admitido que a representação pictórica se dá em um espaço funcional pode ser visto como uma batalha ganha pela abordagem da representação proposicional, ainda que seja possível que os mapas retinotópicos desempenhem algum papel importante no raciocínio imagético. Por outro lado, a proposta de uma linguagem do pensamento ainda não se concretizou, de maneira que podemos dizer que a "guerra" continua.

Aguardemos então as próximas batalhas do conflito, deste que é talvez o mais rico e fecundo debate contemporâneo da ciência cognitiva. 


\section{Bibliografia}

Anderson, J.R. (1978). Arguments concerning representations for mental imagery. Psychological Review 85: 249-77.

Brandt, S.A. \& Stark, L.W. (1997). Spontaneous eye movements during visual imagery reflect the content of the visual scene. Journal of Cognitive Neuroscience 9: 2738.

Bruner, Jerome \& Goodman, Cecile C. (1947). Value and need as organizing factors in perception. Journal of Abnormal and Social Psychology 42: 33-44.

Dalla Barba, G.; Rosenthal, V. \& Visetti, Y.-M. (2002). The nature of mental imagery: how null is the "null hypothesis"? Behavioral and Brain Sciences 25: 187-8. (Comentário a Pylyshyn, 2002.)

Denis, Michel \& Kosslyn, Stephen M. (1999). Scanning visual mental images: a window on the mind. Cahiers de Psychologie Cognitive/Current Psychology of Cognition 18: 409-65. Disponível em: http://www.wjh.harvard.edu/ kwn/ Kosslyn_pdfs/1999Denis_CurrPsycholCog18_ScanningVisualMentalImages.pdf

Dennett, Daniel C. (1969). The nature of images and the introspective trap. In: — Content and consciousness. Londres: Routledge and Kegan Paul, pp. 91-97. Reimpresso in: Block, Ned (org.) (1981). Readings in Philosophical Psychology, vol. 2. Cambridge: Harvard University Press, pp. 128-34.

(1988). Quining qualia. In: Marcel, A. \& Bisiach, E. (orgs.). Consciousness in contemporary science. Oxford: Oxford University Press, pp. 42-77. Reimpresso in: Goldman, Alvin I. (org.) (1993). Readings in philosophy and cognitive science. Cambridge: MIT Press, pp. 381-414. 
(1991). Consciousness explained. Londres: Little, Brown and Co.

(2005). Sweet dreams: philosophical obstacles to a science of consciousness. Cambridge: MIT Press.

Dennett, Daniel C. \& Kinsbourne, Marcel (1992). Time and the observer: the where and when of consciousness in the brain. Behavioral and Brain Sciences 15:183-201. Disponível em: http://ase.tufts.edu/cogstud/papers/time\&obs.htm

Feynman, R.P. (2006). Uma caixa de ferramentas diferente. In: —— O senhor está brincando, Sr. Feynman! Rio de Janeiro: Campus-Elsevier. (Original em inglês: 1985.)

Fodor, Jerry A. (1975). The language of thought. New York: Crowell.

Graham, Graham \& Horgan, Terence (2000). Mary Mary quite contrary. Philosophical Studies 99: 59-74.

Grandin, Temple (1996). Thinking in pictures. New York: Vintage.

Jackson, Frank (1982). Epiphenomenal qualia. Philosophical Quarterly 32: 27-36.

Kolers, P. \& von Grünau, M. (1976). Shape and color in apparent motion. Vision Research 16: 329-35.

Kosslyn, Stephen M. (1973). Scanning visual images: some structural implications. Perception \& Psychophysics 14: 90-94. Online: http://www.wjh.harvard.edu/ $\sim$ kwn/Kosslyn_pdfs/1973Kosslyn_PerceptionPsychophysics14_ScanningVisual ImagesSomeStructralImplications.pdf

(1975). Information represention in visual images. Cognitive Psychology 7: 341-70. Disponível em: http://www.wjh.harvard.edu/ kwn/Kosslyn_pdfs/ 1975Kosslyn_CogPsychol7_InformationRepresentationinVisualImages.pdf 
(1978). Measuring the visual angle of the mind's eye. Cognitive Psychology

10: 356-89. Disponível em: http://www.wjh.harvard.edu/ kwn/Kosslyn_pdfs/ 1978Kosslyn_CogPsychol10_MeasurVisAngleMindsEye.pdf

(1981). The medium and the message in mental imagery: a theory. Psychological Review 88: 46-66. Online: http://www.wjh.harvard.edu/ kwn/ Kosslyn_pdfs/1981Kosslyn_PsycholRev88_TheMediumandtheMessage.pdf

(1983). Ghosts in the mind's machine. New York: Norton.

(1994). Image and brain: the resolution of the imagery debate. Cambridge: MIT Press.

Kosslyn, Stephen M.; Ball, T.M. \& Reiser, B.J. (1978). Visual images preserve metric spatial information: evidence from studies of image scanning. Journal of Experimental Psychology: Human Perception and Performance 4: 47-60. Disponível em: http://www.wjh.harvard.edu/ kwn/Kosslyn_pdfs/ 1978Kosslyn_JExpPsychol4_VisualImagesPreserveMetricSpatialInfo.pdf

Kosslyn, Stephen M.; Thompson, William L. \& Ganis, Giorgio (2002). Mental imagery doesn't work like that. Behavioral and Brain Sciences 25: 198-200. （Resposta a Pylyshyn, 2002.) Disponível em: http://www.wjh.harvard.edu/ kwn/ Kosslyn_pdfs/2002Kosslyn_BehavBrainSci25_MentalImagery.pdf (2006). The case for mental imagery. Oxford: Oxford University Press.

Libet, Benjamin (2004). Mind time: the temporal factor in consciousness. Cambridge: Harvard University Press.

Loar, Brian (1997). Phenomenal states II. In: Block, N.; Flanagan, O. \& Güzeldere, G. (orgs.). The nature of consciousness: philosophical debates. Cambridge: MIT Press, pp. 597-616. Disponível em: http://www.nyu.edu/gsas/dept/philo/ courses/consciousness97/papers/loar.html 
Marr, David (1982). Vision: a computational investigation into the human representation and processing of visual information. New York: Freeman.

Minsky, Marvin (1985). The society of minds. New York: Simon \& Schuster.

Noë, Alva (2002). Is the world a grand illusion? Journal of Consciousness Studies 9: 112.

(2004). Action in perception. Cambridge: MIT Press.

(2008). Précis of Action in perception. Philosophy and Phenomenological Research 76: 660-5.

O’Regan, J. Kevin \& Noë, Alva (2001). A sensimotor account of vision and visual consciousness. Behavioral and Brain Sciences 24: 939-73.

Pylyshyn, Zenon W. (1973). What the mind's eye tells the mind's brain: a critique of mental imagery. Psychological Bulletin 80: 1-24.

(1981). The imagery debate: analogue media versus tacit knowledge. Psychological Review 87: 16-45. Disponível em: http://nwkpsych.rutgers.edu/ jose/courses/578_mem_learn/2012/readings/Pylyshyn_1981.pdf

(1989). Computing in cognitive science. In: Posner, M.I. (org.). Foundations of cognitive science. Cambridge: MIT Press, pp. 51-91. Disponível em http://ruccs.rutgers.edu/ftp/pub/papers/posner.pdf

(2002). Mental imagery: in search of a theory. Behavioral and Brain Sciences 25: 157-82. Disponível em: http://ruccs.rutgers.edu/ftp/pub/papers/ bbs2002_reprint.pdf

(2003). Seeing and visualizing: it's not what you think. Cambridge: MIT Press. 
(2007). Things and places: how the mind connects with the world. Cambridge: MIT Press.

Rensink, R.A.; O'Regan J.K. \& Clark, J.J. (1997). To see or not to see: the need for attention to perceive changes in scenes. Psychological Science 8: 368-73.

Sacks, Oliver (1995). Um antropólogo em marte. São Paulo: Companhia das Letras.

Shepard, Roger N. \& Metzler, Jacqueline (1971). Mental rotation of three-dimensional objects. Science 171: 701-3.

Simon, Herbert A. \& Newell, Allen (1964). Information processing in computer and man. American Scientist 52: 281-300.

Tootell, R.B.H.; Silverman, M.S.; Switkes, E. \& De Valois, R.L. (1982). Deoxyglucose analysis of retinotopic organization in primate striate cortex. Science 218: 902-4.

Tye, Michael (1991). The imagery debate. Cambridge: MIT Press.

(2009). Consciousness revisited: materialism without phenomenal concepts. Cambridge: MIT Press.

Wittgenstein, Ludwig (1993). Tractatus logico-philosophicus. Trad. Luiz Henrique Lopes dos Santos. São Paulo: Edusp. (Original em alemão: 1921.) (1994). Investigações Filosóficas. Trad. Marcos G. Montagnoli. Petrópolis: Vozes. (Original em alemão: 1953.) 